\title{
Plastid transit peptides - Where do they come from and where do they all belong? Multi-genome and pan-genomic assessment of chloroplast transit peptide evolution
}

\author{
Ryan W Christian ${ }^{1}$, Seanna L Hewitt ${ }^{1}$, Grant Nelson ${ }^{1}$, Eric H Roalson ${ }^{1,2}{ }^{,}$Amit Dhingra ${ }^{\text {Corresp. } 1,3}$ \\ 1 Molecular Plant Sciences, Washington State University, Pullman, WA, United States \\ 2 School of Biological Sciences, Washington State University, Pullman, WA, United States \\ 3 Department of Horticulture, Washington State University, Pullman, WA, United States \\ Corresponding Author: Amit Dhingra \\ Email address: adhingra@wsu.edu
}

Subcellular relocalization of proteins determines an organism's metabolic repertoire and thereby its survival in unique evolutionary niches. In plants, the plastid and its various morphotypes import a large and varied number of nuclear-encoded proteins to orchestrate vital biochemical reactions in a spatiotemporal context. Recent comparative genomics analysis and high-throughput shotgun proteomics data indicate that there are a large number of plastid-targeted proteins that are either semi-conserved or non-conserved across different lineages. This implies that homologs are differentially targeted across different species, which is feasible only if proteins have gained or lost plastid targeting peptides during evolution. In this study, a broad, multi-genome analysis of 15 phylogenetically diverse genera and in-depth analyses of pangenomes from Arabidopsis and Brachypodium were performed to address the question of how proteins acquire or lose plastid targeting peptides. The analysis revealed that random insertions or deletions were the dominant mechanism by which novel transit peptides are gained by proteins. While gene duplication was not a strict requirement for the acquisition of novel subcellular targeting, $40 \%$ of novel plastid-targeted genes were found to be most closely related to a sequence within the same genome, and of these, 30.5\% resulted from alternative transcription or translation initiation sites. Interestingly, analysis of the distribution of amino acids in the transit peptides of known and predicted chloroplast-targeted proteins revealed monocot and eudicot-specific preferences in residue distribution. 


\section{Plastid Transit Peptides - Where do they Come from and}

\section{Where do they all Belong? Multi-Genome and Pan-Genomic}

3 Assessment of Chloroplast Transit Peptide Evolution

4

5 Ryan Christian ${ }^{1,2}$, Seanna L. Hewitt ${ }^{1,2}$, Grant Nelson ${ }^{1,2}$, Eric H. Roalson ${ }^{2,3}$ and Amit Dhingra ${ }^{1,2 \S}$

${ }^{1}$ Department of Horticulture, Washington State University, Pullman, WA

$8{ }^{2}$ Molecular Plant Sciences, Washington State University, Pullman, WA

$9{ }^{3}$ School of Biological Sciences, Washington State University, Pullman, WA

$\S$ Corresponding author

Amit Dhingra

adhingra@wsu.edu

Email Addresses:

RWC: ryan_christian@wsu.edu

SH: seanna.hewitt@wsu.edu

GN: grant.nelson@wsu.edu

EHR: eric_roalson@wsu.edu

21 


\section{Abstract}

24

25

Subcellular relocalization of proteins determines an organism's metabolic repertoire and thereby its survival in unique evolutionary niches. In plants, the plastid and its various morphotypes import a large and varied number of nuclear-encoded proteins to orchestrate vital biochemical reactions in a spatiotemporal context. Recent comparative genomics analysis and highthroughput shotgun proteomics data indicate that there are a large number of plastid-targeted proteins that are either semi-conserved or non-conserved across different lineages. This implies that homologs are differentially targeted across different species, which is feasible only if proteins have gained or lost plastid targeting peptides during evolution. In this study, a broad, multi-genome analysis of 15 phylogenetically diverse genera and in-depth analyses of pangenomes from Arabidopsis and Brachypodium were performed to address the question of how proteins acquire or lose plastid targeting peptides. The analysis revealed that random insertions or deletions were the dominant mechanism by which novel transit peptides are gained by proteins. While gene duplication was not a strict requirement for the acquisition of novel subcellular targeting, $40 \%$ of novel plastid-targeted genes were found to be most closely related to a sequence within the same genome, and of these, $30.5 \%$ resulted from alternative transcription or translation initiation sites. Interestingly, analysis of the distribution of amino acids in the transit peptides of known and predicted chloroplast-targeted proteins revealed monocot and eudicot-specific preferences in residue distribution.

Keywords: plastid, transit peptide, signal peptide, pangenome, protein targeting 
46 Introduction

47

48

The endosymbiosis of ancestral cyanobacteria and $\alpha$-proteobacteria by a eukaryote gave rise to the plastids and the mitochondria in a plant cell (Cavalier-Smith, 1987; Bhattacharya et al., 2007). The host genome acquired the majority of the prokaryotic genes, products of which are imported from the cytosol into the organelle to support a myriad of biochemical processes (McFadden, 1999; McFadden \& Van Dooren, 2004). Underlying this intracellular protein import between the nucleic acid harboring organelles was the evolution of the targeting (TP) or signal peptide (SP) (Bruce, 2000).

In plants, the plastid accounts for roughly $10 \%$ of all proteins, $95 \%$ of which must be imported via specialized chloroplast transit peptides (cTPs) (The Arabidopsis Genome Initiative, 2000; Martin et al., 2002; Richly \& Leister, 2004; Ajjawi et al., 2010; Lu et al., 2011; Schaeffer et al., 2014). Evolutionarily speaking, plastids are the most recent organelles; however, their import apparatus is possibly the most complex and dynamic of any organelle. It consists of at least a dozen proteins in the outer and inner chloroplast envelopes as well as soluble cytosolic and stromal chaperones (Bölter \& Soll, 2016). Chloroplasts also have several import complexes in the thylakoid membrane network, requiring further customization of transit peptides (Celedon \& Cline, 2013).

Despite the complexity, cTPs, are inherently unstructured and have poor sequence conservation and are therefore more likely to evolve de novo compared with functional domains of catalytic proteins (Tonkin et al., 2008). Alterations to SP and TP sequences can cause 'subcellular relocalization', which alters the functional environment of the mature protein leading to novel effects without any changes to the mature protein sequence (Byun-McKay \& Geeta, 2007; McKay et al., 2009). Plants and other photosynthetic eukaryotes (algae and protists) may be more affected by changes to subcellular localization due to the presence of chloroplasts, cell wall, and phragmoplasts as distinct subcellular organelles (Pujol, Maréchal-Drouard \& Duchêne, 2007).

In silico prediction methods have reported that gain or loss of transit peptides in gene homologs is widespread (Richly \& Leister, 2004; Schaeffer et al., 2014), and high-throughput proteomics experiments have reported high variability in the proteomes of plastids both between different plastid morphotypes and across species (Wang et al., 2013; Suzuki et al., 2015). While plastid biology studies have traditionally focused on a few model organisms, including 
77 Arabidopsis and tomato, it is becoming clear that they are not sufficient to describe plastid 78 diversity fully.

To illustrate the preceding notion, a related study analyzed plastid diversity in fruit peel of apple (Malus $\times$ domestica). It was shown that epidermal plastids and collenchymal plastids adopt distinct morphologies during development, pointing to differences in the diversity or regulation of plastid proteomes (Solymosi \& Keresztes, 2013; Schaeffer et al., 2017). Various distinctive plastid morphotypes have been described in fruit or other specialized tissues of different species (Solymosi \& Keresztes, 2013; Wang et al., 2013). New plastid morphotypes which play essential and specialized roles in plant growth and development continue to be discovered, such as the recently-described phenyloplast, which accumulates phenylglucosides in vanilla orchid (Brillouet et al., 2014) and the tannoplast, which synthesizes and exports tannin precursors (Brillouet et al., 2013).

A preceding comparative genomics study analyzed 15 plant genomes and two pangenomes to predict the diversity of the plastid proteome (Christian et al., 2020). The primary conclusion was that non-conserved, species- or taxa-specific proteins are more abundant than conserved plastid-targeted proteins in the overall plastid proteome. Conserved proteins accounted for less than $15 \%$ of the total number of plastid-targeted pan-proteome. Within individual species, they were outnumbered by semi- to non-conserved proteins by a factor of at least 2-to-1 (Christian et al., 2020). These observations raise a fundamental biological question: How do proteins in different plant species acquire plastid-targeting peptides?

There is evidence of various mechanisms that either individually or in some combination may have contributed to the acquisition of a targeting peptide in proteins marked for import into the plastid. Plastid-targeted genes originated from the ancestral prokaryote and were subsequently re-targeted to the plastid, likely following gene duplication (Richly \& Leister, 2004; Byun-McKay \& Geeta, 2007). This mechanism could be a significant contributor to the evolution of novel plastid-targeted proteins, especially when the original gene is of critical importance in its native subcellular location. Also, plastid transit peptides are acquired from heterologous loci via exon shuffling either through unequal recombination or movement of retrotransposons (Vibranovski, Sakabe \& De Souza, 2006). Furthermore, many plastid transit peptides are encoded by distinct exons (Bruce, 2000). Alternative transcriptional or translational start sites could either skip or unmask a buried transit peptide, resulting in dual localization of 
108 the two isoforms; such dual localization occurs in at least 47 proteins and is predicted to occur in 109 up to 400 in Arabidopsis (Carrie, Giraud \& Whelan, 2009; Mitschke et al., 2009). The use of 110 alternative start sites in "twinned presequences" is widespread among proteins which are dual111 targeted to the chloroplast and mitochondria, (Small et al., 1998; Peeters \& Small, 2001;

112 Mackenzie, 2005)

113 The emergence of single nucleotide polymorphisms (SNPs), insertions or deletions

114 (indels), or splice site alterations might underlie the evolution of SPs and TPs as well (Davis et 115 al., 2006; Byun-McKay \& Geeta, 2007; McKay et al., 2009). Minor changes to the N-terminal 116 targeting region of a protein can change its affinity for the chloroplast translocons and alter 117 targeting efficiency. An interesting hypothesis states that such minor changes causing "minor 118 mistargeting" could initiate subcellular relocalization events to plastids and other organelles that 119 occur over greater evolutionary periods (Martin, 2010). It has been suggested that the difference 120 in the charge generated due to mutations on the SP could favor targeting either the plastid or the 121 mitochondria. Phosphorylation of the residues adds a negative charge favoring translocation to 122 the plastid compared to an overall positive charge, which favors targeting to the mitochondrion 123 (Garg \& Gould, 2016). It has also been proposed that plastids and mitochondria were derived 124 from microbes that had developed a resistance strategy against antimicrobial proteins by 125 internalizing and proteolytically destroying them using specific peptidases (Wollman, 2016). 126 By examining experimentally validated and predicted plastid transit peptides from 127 multiple plant species, the hypothesis that transit peptides evolve via simple substitutions, 128 insertions, and deletions, or alternative start sites was tested. The term 'Nascent' was used to 129 designate evolutionarily newly emergent TP sequences in the genes analyzed in this study. 130 Nascent Plastid-targeted Proteins (NPTPs) were identified in a diverse range of angiosperms, and 131 potential evolutionary mechanisms were evaluated to determine which, if any, are most common. 132 Further, the above-mentioned hypothesis was also tested at the intraspecies level using the pan133 genomes of Arabidopsis thaliana and Brachypodium distachyon.

\section{Methods}

\section{Clustering gene families and subcellular prediction}


137 For the Multi-Genome dataset, predicted proteomes from Amborella trichopoda, Arabidopsis

138 thaliana, Brachypodium distachyon, Fragaria vesca, Glycine max, Malus $\times$ domestica, Oryza

139 sativa, Panicum virgatum, Populus trichoarpa, Prunus persica, Setaria italica, Solanum

140 lycopersicum, and Sorghum bicolor were downloaded from phytozome

141 (https://phytozome.jgi.doe.gov). Transcriptome-based gene models were utilized for Anthurium 142 amnicola and Vitis vinifera (Vitulo et al., 2014; Suzuki et al., 2017). For Malus $\times$ domestica, a

143 supplementary transcriptomics-based predicted proteome was created using the SRA datasets

144 from (Krost, Petersen \& Schmidt, 2012; Gusberti, Gessler \& Broggini, 2013; Krost et al., 2013;

145 Bai, Dougherty \& Xu, 2014; Petersen et al., 2015) and assembled using CLC Genomics

146 Workbench v.8 (Qiagen Bioinformatics, Hilden, Germany). For the Arabidopsis1001 dataset,

147 protein sequence files from 246 accessions cataloged in the Arabidopsis1001 proteomes project

148 (Joshi et al., 2012) were downloaded from the Arabidopsis 1001 Proteomes Portal ("1001

149 Proteomes"). Sequences were sorted into single gene files using the reference Columbia-0 gene

150 ID. In the BrachyPan dataset, protein sequences files were downloaded from the BrachyPan

151 website ("BrachyPan") and grouped into orthologous protein clusters using resources by Dr.

152 John Vogel (Gordon et al., 2017). For all species, poorly annotated sequences were removed if

153 no BLAST hits above $40 \%$ identity and $40 \%$ coverage were found for other sequences within the

154 same dataset. Clustering of homologous proteins was performed using two parallel methods.

155 First, reciprocal-best-BLAST hits (RBH) were generated by performing ALL-V-ALL BLASTP

156 comparisons of the predicted proteome of each species against those of every other species.

157 Sequences for each genome pair which were the mutual best hits above $40 \%$ identity and $40 \%$

158 coverage were kept as initial cluster connections. Initial clusters were expanded using reciprocal

159 better-BLAST hits within each genome, performed using ALL-V-ALL BLASTP comparisons of

160 the predicted proteome of each species against itself. Sequences which had mutual hits above

$16190 \%$ identity and 90\% coverage were kept. All cluster edges were collapsed to form clusters. In

162 the second method, the UCLUST algorithm (Edgar, 2010) was executed on a concatenated,

163 length-sorted sequence file of the predicted proteomes of all fifteen species using a $40 \%$ identity

164 and 40\% coverage threshold. From these initial clusters, random sequences from within each

165 cluster, sorting these sequences by length, concatenating them to the beginning of the length-

166 sorted initial sequence file, and re-running using a 90\% identity threshold, minimum of $40 \%$

167 coverage, and maximum target length of $2.5 \mathrm{x}$ the query length. This randomized seed method

PeerJ reviewing PDF | (2019:12:43773:1:2:NEW 5 Jul 2020) 
168

169

170

171

172

173

174

175

176

177

178

179

180

181

182

183

184

185

186

187

188

189

190

191

192

193

194

195

196

197

198

was iterated 100 times, and all clusters from the initial run and subsequent iterations were condensed if they shared at least one sequence. From both RBH and UCLUST methods, clusters were selected which contained at least three species and only a single species with a predicted plastid-targeted sequence (Christian et al., 2020).

Unique sequences from each dataset were analyzed with TargetP v.1.1 (Emanuelsson et al., 2000, 2007) and Localizer v.1.0.2 (Sperschneider et al., 2017) using default program parameters. All sequences predicted by both methods to have chloroplast localization were determined to be plastid-localized, and sequences predicted by one or neither method were determined to be nonplastid-targeted. Custom scripts are available in Supplemental File 6.

\section{Transit Peptide Analysis}

Experimentally-validated proteomics data were retrieved from PPDB (Sun et al., 2009), AT_CHLORO (Ferro et al., 2010), SUBA4 (Hooper et al., 2017), CropPAL, and CropPAL2 (Hooper et al., 2015). Non-redundant sequences validated by mass spectrometry and with unambiguous localization were extracted and residue composition and positional frequency within the 60 residues comprising the transit peptide and all downstream residues comprising the mature protein were analyzed. For the analysis of in silico prediction methods, all sequences with a predicted plastid transit peptide from each species used in the multi-genome dataset were similarly analyzed for residue composition and positional frequency.

\section{Phylogenetics}

All clusters derived for the multi-genome, Arabidopsis1001 and BrachyPan datasets were trimmed of poorly-aligned sequences before phylogenetic analysis using a BLAST filter to remove any sequences with less than $40 \%$ identity and $40 \%$ coverage to any of the predicted plastid-targeted sequences. Maximum likelihood phylogenetic trees were constructed for each cluster using MAFFT v. 7.407 (Katoh et al., 2002; Katoh \& Standley, 2013), and trimmed with Phyutility v2.2.6 (Smith \& Dunn, 2008). Pasta v.1.0 (Mirarab et al., 2015) and FastTree 2.1.10 (Price, Dehal \& Arkin, 2010) were used for alignments of trimmed files, and phylogenetic trees were constructed using RAxML v. 8.2.31 (Stamatakis, 2006, 2014). The point of divergence between plastid-targeted and non-plastid-targeted sequences for each gene cluster was performed 
199

200

201

202

203

204

205

206

207

208

209

210

211

212

213

214

215

216

217

218

219

220

221

222

223

224

225

226

227

228

229

using a custom Perl script (Supplemental file 6) and determined by examination of branch lengths in Newick-formatted maximum likelihood trees. Clusters in which predicted plastidtargeted sequences arose more than once were discarded as probable examples of the polyphyletic origin or ambiguous targeting sequence. Additionally, clusters in which a transit peptide was gained and then lost or in which a plastid-targeted sequence rooted the tree were discarded. Second sequence alignment was performed on the divergent pairs of sequences using MUSCLE v.3.8.31. Mutations within the transit peptide region were defined as the part of the alignment corresponding to the first 60 residues of the plastid-predicted sequence, and the mature region was considered to be the remainder of the alignment. Frequency of substitutions and residue classes was collected for all sequences. Alignments which started with a gap but in which the first aligned residue was a methionine in both sequences were classified as alternative start sites. Alignments with insertion of at least ten residues followed by a deletion of at least ten residues, or vice versa, were categorized as alternative first exons. Finally, alignments in which more substitutions occurred than gaps were classified as substitution-dominant, while alignments fulfilling the reverse criteria were classified as insertion or deletion-dominant.

\section{Gene Ontology}

Annotations for NPTPs were retrieved from Phytozome (https://phytozome.jgi.doe.gov) for each of the species used in the analysis except Anthurium amnicola and Vitis vinifera, which were retrieved from (Suzuki et al., 2017) and (Vitulo et al., 2014), respectively. Annotations for BrachyPan were retrieved from the supplementary materials Gordon et al. (2017). Nonredundant predicted proteins produced by the de novo transcriptome assembly of Malus $\times$ domestica as described previously (Christian et al., 2020) were annotated using BLASTP against the NR Protein database at NCBI with BLAST2GO default parameters (Conesa et al., 2005; Conesa \& Götz, 2008) (BioBam Bioinformatics, Valencia, Spain). GOslim annotations were retrieved using BLAST2GO. Over- and under-represented GO terms for each dataset was performed using BLAST2GO. Fisher's Exact Test was used to calculate significance, and all terms below a false discovery rate (FDR) significance threshold of 0.05 or p-value threshold of 0.05 were extracted.

\section{Results and Discussion}


230 Residue Analysis of Experimentally-validated and Predicted Transit Peptides

231 Although chloroplast transit peptides lack significant homology or functional motifs, they are

232 well-documented to be enriched in certain amino acids and biochemical classes and deficient in

233 others. A comprehensive analysis was conducted using the amino acid content and sequence of a

234 set of 10,868 non-redundant sequences validated by mass spectrometry available in the PPDB

235 (Sun et al., 2009), AT_CHLORO (Ferro et al., 2010), SUBA4 (Hooper et al., 2017), and

236 CROPPAL2 (Hooper et al., 2015) databases. These sequences were primarily derived from

237 Arabidopsis, but also contained significant numbers of proteins from rice and maize and a

238 smaller percentage of proteins from other plant species. The transit peptide was defined as the

239 first 60 amino acids of each experimentally-validated or predicted plastid-targeted protein. Most

240 cleaved transit peptides are 41-70 residues long with an average of 51-60 residues (Kleffmann et

241 al., 2007; Huang et al., 2009; Bienvenut et al., 2012; Teixeira \& Glaser, 2013), but measuring the

242 length of a transit peptide based on its cleavage site is not necessarily a good determinant of its

243 functionality. For instance, the mature protein can exhibit constraints on an otherwise functional

244 transit peptide, causing it to lose translocation functionality or efficiency (Rolland, Badger \&

245 Price, 2016). Additionally, the transit peptide residues upstream of the signal peptide peptidase

246 (SPP) cleavage site in many cases is insufficient to target GFP efficiently to the chloroplast, but

247 the addition of some downstream sequence restores plastid translocation (Comai et al., 1988;

248 Van't Hof et al., 1991; Pilon et al., 1995; Rensink, Pilon \& Weisbeek, 1998; Lee et al., 2008;

249 Shen et al., 2017). A transit peptide of sixty residues in length enables high-efficiency import in

250 most plastid-targeted proteins, so that was used as the standard length of transit peptides for this

251 analysis.

252

253 The average residue composition of experimentally-validated transit peptides was compared to

254 the TAIR10 Arabidopsis proteome, revealing multiple residues with altered abundance (Table 1,

255 Figure 1, Supplemental File 1). Transit peptides were enriched in alanine (+64.1\%), proline

$256(+52.4 \%)$, arginine $(+41.6 \%)$, serine $(+35.5 \%)$, and threonine $(+11.1 \%)$, a composition well

257 established in the literature [e.g. (Bruce, 2001; Zybailov et al., 2008)]. Also, as described in the

258 literature, depletion of the negatively-charged glutamic acid (-46.3\%) and aspartic acid (-43.4\%)

259 and the aromatic amino acids tryptophan (-36.8\%), and tyrosine (-38.6\%) was observed.

260 However, depletion of isoleucine (-24.3\%), asparagine (-28.6\%), lysine (-22.4\%), and glutamine 
$261(-16.1 \%)$ were seen relative to the average TAIR residue composition, none of which have been

262 documented before in plastid transit peptides. Additionally, while tyrosine and tryptophan were 263 depleted in transit peptides, phenylalanine was relatively neutral (-7.9). Phenylalanine is a

264 distinguishing feature of Rhodophyta and Glaucophyta transit peptides and is present in the

265 "FGLK" motif described for preferredoxin and preSSU (Pilon et al., 1995; Wienk et al., 2000;

266 Mcwilliams, 2007; Patron \& Waller, 2007). While McWilliams (2007) describes either

267 tryptophan or phenylalanine as required for preSSU high-efficiency import, but it may be that

268 phenylalanine is preferred as a relic of ancestral import mechanisms. The observed decrease in

269 average lysine content is unusual, as early reports suggested that the C-terminal or distal end of

270 transit peptides is enriched in positively-charged residues, including both arginine and lysine

271 (Bruce, 2000; Zhang \& Glaser, 2002). Additionally, glycine and valine - although abundant in

272 transit peptides at about $6 \%$ of residues each - were underrepresented in comparison to average

273 proteome sequence, indicating that they are detrimental or relatively neutral to the function of

274 plastid transit peptides. Overall, these data suggest that bulky R groups are generally not favored

275 in transit peptides unless they serve a special purpose, such as the highly-enriched arginine,

276 which is proposed to interact with TOC33 and TOC159 during translocation (Vetter \&

277 Wittinghofer, 2001; Jelic, Soll \& Schleiff, 2003).

278

279 Figure 1: Amino Acid Compositional Changes in Transit Peptides. The first 60 residues of

280 Arabidopsis proteins validated by mass spectrometry were analyzed for residue composition and 281 compared with the average residue composition of all Arabidopsis proteins. Enrichment of 282 alanine, proline, arginine, and serine, while depletion of aspartic acid, glutamine, isoleucine, 283 lysine, asparagine, and tyrosine was observed. Although glycine, leucine, threonine, and valine 284 were abundant, they did not differ significantly from the average residue content in Arabidopsis 285 proteins.

286

287 Plastid transit peptide composition is not homogenous but is instead organized in three major 288 domains, as described by the several models of transit peptide structure (Karlin-Neumann \& 289 Tobin, 1986; Quigley, Martin \& Cerff, 1988; Bruce, 2000, 2001; Li \& Teng, 2013). These three 290 domains include an uncharged $\mathrm{N}$-terminal proximal region, a central domain rich in 291 hydroxylated residues and lacking acidic residues, and a C-terminal distal region enriched in 
292 arginine (Bruce, 2001), corresponding roughly to regions of the transit peptide which interact

293 primarily with the TIC translocase and HSP motor complex, the TOC75 POTRA domains, and

294 the TOC33/159 GTPases, respectively (Richardson et al., 2018). The positional bias of each

295 amino acid was therefore observed for both experimentally validated transit peptides confirmed

296 using mass spectrometry, as well as in putative transit peptides predicted by a combination of

297 TargetP 1.1 and Localizer (Table 1, Figure 2) (Christian et al., 2020).

298 TargetP 2.0 (Juan et al., 2019) was released soon after the conclusion of this analysis. To

299 evaluate the performance of TargetP 2.0 dataset representing experimentally-validated proteins

300 totaling 650 plastid-targeted proteins and 3072 non-plastidial proteins was used. Three key

301 observations were made regarding the performance of TargetP 2.0: 1. Stand-alone TargetP 2.0

302 performed better than TargetP 1.1 in terms of specificity, which increased by $30.7 \%$. The MCC

303 and accuracy increased by 0.121 and $5.1 \%$, respectively. There was a decrease in sensitivity by

$30411 \%$ compared to the previous version (Supplemental File 2, Tab 1). However, it was not better

305 than the combined approaches. 2. The best workflow of TargetP 1.1 plus Localizer used in this

306 study, and TargetP 2.0 plus Localizer had the same MCC and accuracy values. With TargetP 2.0,

307 the sensitivity actually decreased by $8.2 \%$, and the specificity increased by $9.4 \%$. The overall

308 performance, therefore, was not significantly different. 3. The best workflow with TargetP 2.0

309 was a 2 of 3 approach in combination with Localizer and MultiLoc, however it was equivalent in

310 performance with TargetP 1.1 plus Localizer. There was a marginal increase of $5.5 \%$ in

311 specificity. In our experience, the replacement of TargetP 1.1 with TargetP 2.0 produced

312 runtime error during the processing of the larger datasets, that were initially processed with ease

313 using TargetP 1.1. With the improvements in TargetP 2.0 performance and potential inclusion of

314 machine learning approaches there may be an opportunity to obtain high-quality predictions

315 using any combination of the workflows reported in this work. Therefore, for TP residue

316 analysis, the plastid-targeted proteins predicted using the TargetP 1.1 plus Localizer workflow

317 were used (Christian et al., 2020).

$318 \quad$ For all residues, nearly identical distribution patterns were observed between

319 experimental (solid lines) and predicted plastid transit peptides (dotted lines) (Figure 2), thus

320 confirming that the prediction methods selected in this study corresponded well with

321 experimentally validated residues. However, the actual frequency was often somewhat different,

322 as predicted transit peptides had a higher frequency of the more abundant amino acids compared 
323 to experimentally-validated proteins, especially serine, arginine, and proline. Serine was nearly

$3245 \%$ more frequent (absolute frequency) in predicted transit peptides despite the higher proportion

325 of Monocot sequences that should dilute its frequency. Proline was also overestimated by $2-4 \%$

326 depending on the position, and arginine was overrepresented by about $2 \%$ after position 15 .

327 Conversely, predicted transit peptides were underrepresented in rare/neutral or distally-enriched

328 amino acids such as aspartic acid, glutamic acid, glycine, valine, and tyrosine. These

329 observations point to a possible systemic bias in the software, which may focus only on the most

330 essential components. However, the patterns and generally close abundances indicate that

331 prediction tools achieve results that are similar to the experimental methods.

332

333 Several amino acids, including alanine, leucine, serine, threonine, and methionine were more

334 abundant at the proximal end of transit peptides. They declined significantly in frequency over

335 the length of the transit peptide (Figure 2). Of these, all except methionine were found at initial

336 frequencies greater than 5\%. Serine alone is initially present at about $17 \%$ frequency, while the

337 small nonpolar amino acids alanine and leucine together comprise $25 \%$ of residues in the

338 proximal third of the transit peptide. The second category of centrally-enriched amino acids,

339 including proline, arginine, phenylalanine, and histidine, are initially low in abundance, rise to a

340 peak value between positions 10-30, then decrease in frequency across the remaining length.

341 Arginine reaches a peak value somewhat later than the other three, peaking instead between

342 positions 20 and 40 . Histidine was rare among this group, present at only $1.5 \%$ at the proximal

343 end and increasing to a high of only $3 \%$ at position 20 , though its trend matched that of other

344 centrally-enriched residues. The third group of residues which were initially rare but increased in

345 frequency across the length of the transit peptide and reached a peak in the distal end included

346 lysine, aspartic acid, glycine, and glutamic acid. Both glutamic and aspartic acids followed a

347 small but consistent trend, starting at about 3.5\% each for every position at the beginning of the

348 cTP and increasing gradually to a high of 5\% for aspartic acid, and $6 \%$ for glutamic acid. To the

349 best of our knowledge, such a trend has not been reported before, but a 2-fold increase of these

350 residues between the proximal and distal ends of the transit peptide is evident in both

351 experimentally-validated and predicted sequences. From what is known of the TOC GTPases,

352 the primary means of selectivity is due to the hypervariable acidic A-domain of the TOC159

353 family (Smith et al., 2004; Richardson, Jelokhani-Niaraki \& Smith, 2009; Inoue, Rounds \& 
354 Schnell, 2010). It is possible that the pattern that was observed for negatively-charged amino

355 acids in the distal GTPase-interacting domains of transit peptides is further evidence of these 356 exclusion motifs that alter import efficiency, perhaps by charge repulsion against the acidic TOC 357 GTPase A-domain (Smith et al., 2004). A final group of residues were either very rare $(<2 \%)$ or 358 exhibited more moderate fluctuations in frequency across the length of the transit peptide, and 359 included valine, glutamine, cysteine, asparagine, isoleucine, tyrosine, and tryptophan.

360

Figure 2 A-T: Residue Frequency in Predicted and Experimentally-Validated Transit

Peptides. A - Alanine, B - Cysteine, C - Aspartic acid, D- Glutamic acid, E - Phenylalanine, FGlycine, G - Histidine, H - Isoleucine, I - Lysine, J - Leucine, K - Methionine, L - Asparagine, $\mathrm{M}$ - Proline, $\mathrm{N}$ - Glutamine, $\mathrm{O}$ - Arginine, $\mathrm{P}$ - Serine, $\mathrm{Q}$ - Threonine, $\mathrm{R}$ - Valine, $\mathrm{S}$ Tryptophan, and T - Tyrosine. The first 60 residues of sequences validated to be plastid-targeted by mass spectrometry methods (solid lines) and of predicted plastid-targeted proteins in 15 plant genomes (dotted lines) were collected, and residue composition was assessed for each position. Positions 1 and 2 are omitted from each graph due to skew by methionine and alanine, respectively. Frequency patterns match almost exactly between experimentally-validated and predicted plastid-targeted proteins, but there are differences in the absolute frequency for many amino acids, in particular, highly-enriched and highly-depleted residues.

372

Transit peptides of different plant taxa may have inherent differences due to genetic drift, to the binding affinity of the TOC and TIC translocon receptors, or to expansion or contraction of gene families for translocon and chaperone subunits. For instance, transit peptides of monocots and eudicots have previously been reported to be enriched in alanine and serine, respectively (Zybailov et al., 2008). Therefore, the amino acid content of sequences from predicted plastid transit peptides of six monocots (Anthurium amnicola, Brachypodium distachyon, Oryza sativa, Panicum virgatum, Setaria italica, and Sorghum bicolor), eight eudicots (Arabidopsis thaliana, Fragaria vesca, Glycine max, Malus $\times$ domestica, Populus trichocarpa, Prunus persica, Solanum lycopersicum, and Vitis vinifera), and the extant angiosperm species Amborella trichopoda was compared to determine if these trends held true, or if other amino acid biases occurred in certain taxa (Table 1, Figure 3A). In all genotypes, serine was found to be 
385

386

387

388

389

390

391

392

393

394

395

396

397

398

399

400

401

402

403

404

405

406

407

408

409

410

411

412

413

414

was more abundant with $30 \%$ more serine on average compared with monocot transit peptides. In contrast, alanine was marginally enriched in the transit peptides over whole proteome sequence in eudicots but was extremely enriched in monocots, with a minimum of $+50.7 \%$ enrichment in $A$. amnicola up to a high of $+81.1 \%$ in $O$. sativa compared to the respective whole proteome. In eudicots, a maximum of only $+16.7 \%$ alanine enrichment was found in Malus $\times$ domestica transit peptides $(+16.7 \%)$, whereas those of Populus trichocarpa were underrepresented (-1.0\%). Alanine was the most abundant amino acid of monocot transit peptides for all genotypes except $A$. amnicola, and overall, was enriched by $111.6 \%$ compared with eudicot transit peptides, whereas serine was the most abundant amino acid in all eudicot genotypes. Alanine is somewhat enriched in the whole proteome of monocot species, but this trend is insufficient to explain these results (Figure 3B). Alanine enrichment in monocot transit peptides was counterbalanced by depletion of phenylalanine (-91.3\%), isoleucine $(-105.4 \%)$, leucine (-121.5\%), asparagine (-169.8\%), glutamine (-35.6\%), and threonine $(-34.2 \%)$ compared with eudicots. Tyrosine was also significantly underrepresented (-60.1\%) in monocots, although its frequency is extremely low in both clades. Eudicots had somewhat lower glycine, proline, and arginine. Overall, transit peptides of monocots contain more small, nonpolar amino acids, including glycine, valine, and proline, in comparison with eudicots, which have a more flexible amino acid composition. Furthermore, arginine, which is essential in binding and interaction with the TOC GTPases, was relatively higher in monocot sequences (Pilon et al., 1995; Rensink, Schnell \& Weisbeek, 2000). One possibility that explains these differences is that changes to monocot translocons select for more conserved transit peptides. Monocots lack all but one isoform of the core TIC subunit TIC20, and also lack the suspected TIC component Ycf1 compared with eudicots (de Vries et al., 2015; Nakai, 2015; Bölter \& Soll, 2017). If these missing components impact import efficiency or selectivity, their loss in monocots may favor small, uncharged amino acids in the transit peptides to minimize steric hindrance, and necessitate a higher arginine content to ensure high import efficiency. As research progresses on the nonessential components of TIC such as TIC100, TIC56, and Ycf1, it will be interesting to see if they have a role in increasing import efficiency for transit peptides with unfavorable amino acids. 
415 Figure 3: Residue Composition of Predicted Transit Peptides and Whole Proteome

416 Sequence. (A) Residue composition of predicted transit peptides shows significant enrichment in

417 alanine, leucine, proline, arginine, and serine in all assessed organisms, but monocot homologs

418 were highly overrepresented in alanine, proline, and arginine. Corresponding decreases in serine,

419 and many of the minor amino acids, including phenylalanine, isoleucine, lysine, and asparagine,

420 were also found in monocot sequences. A. trichopoda sequences closely matched eudicot

421 sequences. (B) Alanine was about 2\% higher within the whole proteomes of monocot species,

422 but this does not explain the extreme differences found for predicted transit peptides.

423

424

In $A$. trichopoda, it was expected that the transit peptides would have intermediate residue composition between monocots and eudicots because it is the sister lineage to the combined monocot/eudicot lineage (Soltis et al., 2009; Albert et al., 2013). Surprisingly, however, predicted transit peptides in $A$. trichopoda were nearly identical to eudicots for almost all residues. Slightly intermediate values were observed for some residues (e.g., lysine, asparagine, proline, glutamine, and serine), but even in these cases, these sequences more closely resembled eudicot rather than monocot sequences. The only residues with a significantly different trend were valine, which was somewhat decreased compared to both monocots and eudicots, and glutamic acid, which was slightly elevated in both. This result seems to indicate that monocots have experienced changes to an ancestral protein translocation machinery, and this change has selected for different amino acid content in transit peptides.

Evolution of Nascent Plastid Transit Peptides (NPTPs) in Diverse Angiosperm

To test the hypothesis that transit peptides evolve in predictable patterns, NPTPs were first examined among comparative homologous protein clusters detected using either ReciprocalBest-BLAST hits $(\mathrm{RBH})$ or UCLUST. Plastid targeting prediction was performed using a consensus approach of TargetP 1.1 and Localizer, which has been shown recently to be highly efficient at predicting plastid targeting (Christian et al., 2020). Both prediction methods were mined for clusters containing at least three species and in which only one species had predicted plastid-targeted proteins were identified. If the reciprocal method found that this sequence was not uniquely plastid-targeted, it was determined to have moderate support by only a single 
446

447

448

449

450

451

452

453

454

455

456

457

458

459

460

461

462

463

464

465

466

467

468

469

470

471

472

473

474

475

476

method. In total, 1,328 clusters were supported by both methods, 618 clusters were detected using RBH only, and 1,443 clusters in UCLUST only. Phylogenetic trees were constructed for each cluster using MAFFT, Phyutility, and RAxML, and the resulting alignments were examined for evolutionary patterns in the transit peptides. All clusters containing multiple unlinked branches of chloroplast transit peptides, losses of transit peptides within a branch, or predicted chloroplast-targeted sequences at the root of the phylogenetic tree were removed in order to focus on single, recent transit peptide acquisitions in single genes (Figure 4, Table 2). Data were examined for the causal mechanisms of transit peptide evolution, including substitutions, insertions/deletions, and alternative start sites (Figure 5). Results from the three detection methods were pooled, and the responsible mutations for transit peptide evolution were summarized (Table 3, Figure 6, Supplemental File 3).

Figure 4: Illustration of Phylogenetics Workflow. For each candidate cluster representing a potential NPTP, the steps for filtering, alignment, tree prediction, and mutation analysis are depicted. Blue boxes indicate the path of candidate clusters, red boxes indicate sequences or clusters that are filtered out, green boxes indicate the potential mutational categories, and programs or conditions used in the workflow are indicated to the right of arrows.

Figure 5 A-D: Models of Transit Peptide Evolution. A - Substitution, B - Alternative initiation exon, $\mathrm{C}$ - Alternative slice variant, and D - Alternative start site. In each panel, exons are indicated with shaded boxes and introns with black lines. The ancestral RNA molecule is indicated in black, and variants are indicated in light green. Substitution variants are the only mechanism requiring a change to the DNA sequence, although sequence variants may also promote or hinder the other mechanisms. Adapted from Davis et al., 2006.

Residue substitutions were the primary evolutionary factor for $31.4 \%$ of NPTPs, with an average of 12.3 substitutions per divergent pair (Figure 6A). Substitutions were somewhat concentrated at the proximal N-terminal third of the transit peptides (Figure 6B). Just $34.8 \%$ of residue substitutions conserved the same biochemical properties (overall charge, size, and polarity). Of the remainder, nonpolar to polar substitutions and polar to nonpolar substitutions were most common, at $23.7 \%$ and $16.2 \%$ of the total, respectively. De novo evolution of transit peptides by 
477 single or multiple residue substitutions has been suggested as a primary mechanism of transit

478 peptide evolution (Byun-McKay \& Geeta, 2007). Signal peptides evolve two times faster than

479

480

481

482

483

484

485

486

487

488

489

490

491

492

493

494

495

496

497

498

499

500

501

502

503

504

505

506

507 mature proteins on average, and up to 5-6 times faster than random sequence (Williams et al., 2000). Among the sequence pairs in the multi-genome dataset, the transit peptide region shared just $37.9 \%$ identity compared with $65.6 \%$ identity in the downstream mature protein. The first ten residues of transit peptides are known to strongly influence import efficiency

(Chotewutmontri et al., 2012; Chotewutmontri \& Bruce, 2015), so simple substitutions in this region could impart novel plastid targeting of the cargo protein more easily. Similar trends in amino acid enrichment and depletion were observed for both substitutions and insertions/deletions (Figure 6C). Surprisingly, the absolute abundance and distribution of small insertions and deletions was relatively similar, but insertions became much more prevalent after the 20-residue range (Figure 6D). For indel mutations affecting the entire 60-residue window of the putative transit peptide, insertions were over three times more common than deletions. On average, 25.6 positions were inserted, and 12.2 positions were deleted for each NPTP sequence alignment- $49.8 \%$ of all NPTPs. Alternative start sites upstream of the ancestral sequence were responsible for $29.4 \%$ of NPTP's while those at a downstream positions accounted for only 8.7\%. Both alternative start sites (Davis et al., 2006) and exon shuffling (Long et al., 1996; Vibranovski, Sakabe \& De Souza, 2006) have been suggested as primary drivers of subcellular relocalization, and evidence supporting both mechanisms was found in this analysis. Most insertions and deletion mutations occurred at the beginning and aligned on an initial methionine in the shorter sequence, suggesting that they are alternative start sites (Table 3); however, alterative start sites did not account for all insertions or deletions occurring at the 5 ' end, suggesting that exon shuffling may also play a significant role. The potential impact of alternative first exons was also examined, but no candidates were detected. However, as the analysis focused on the first 60 amino acids, it is possible that instances in which the first exon was longer were missed. Additionally, only exons of at least ten residues in length were examined for possible alternative exons, which may have excluded microexons (Guo \& Liu, 2015).

Figure 6: Mutation Sources in Multi-Genome NPTPs. Merged results for RBH, UCLUST, and Consensus datasets are presented. (A) Clusters in which an upstream alternative start site 
508 caused the acquisition of a transit peptide were most abundant, followed by substitutions and

509

510

511

512

513

514

515

516

517

518

519

520

521

522

523

524

525

526

527

528

529

530

531

532

533

534

535

536

537

538 insertions. Deletions were comparatively rare. (B) A slight but significant linear decrease in the amino acid substitution frequency at each position was observed, indicating that positions at the proximal end of the $\mathrm{N}$-terminus have a greater effect on transit peptide prediction strength. (C) Arginine, proline, and serine experienced significant net increases, while aspartic acid, glutamic acid, and glycine all experienced more than $2 \%$ net decrease when nascent transit peptides were compared to the closes non-targeted neighbor sequence. Net change of amino acids was generally similar between substitutions and insertions/deletions, but proline and arginine were far less likely to be acquired due to substitutions. (D) Most insertions and deletions were between 15 amino acids in length and generally decreased in frequency as the size increased. However, elements that covered the entirely 60-residue length of the transit peptide region were extremely abundant, especially those caused by insertions.

In $48.6 \%$ of clusters, the most closely related predicted non-plastid-targeted sequence was from within the same genome, strongly implying that either gene duplication or alternative splicing caused the evolution of a novel transit peptide in these cases. Overwhelmingly, novel plastidtargeted sequences were derived from gene duplication events: only $27.9 \%$ of NPTP's evolving from a protein from the same species, or $13.6 \%$ of the NPTP total, were due to alternative gene products or alleles of the same locus. Because relocalization of the protein from its native environment into the chloroplast would create a de facto knockout phenotype by removing its natural localization, gene duplication or alternative isoforms may be necessary to maintain the evolutionary function of the original gene or transcript while giving flexibility for the duplicated copy to evolve a new function. However, as the majority of clusters were not duplicated, either the current proteomes are not fully annotated, or duplication is not strictly required for subcellular relocalization.

To firstly confirm that terms associated with plastids are underrepresented or neutral, and secondly, to uncover any overrepresented terms to discover functions that are broadly selected for in novel plastid-targeted genes, GO enrichment of NPTPs was conducted. A custom dataset consisting of the full proteomes from each of the included species was used as a reference dataset. As expected for non-conserved plastid-targeted proteins, terms associated with plastid 
539 (GO:0009536), thylakoid (GO:0009579), localization (GO:0051179, GO:0051234), and

540 transport (GO:0006810), were significantly underrepresented, as shown in Table 4. A total of 49

541 terms were overrepresented in this dataset, almost all of which were associated with metabolism

542 and biosynthesis, regulation of gene expression, and protein binding or regulation. Most

543 biosynthetic terms were associated with primary metabolism, but several terms involved in

544 heterocyclic and aromatic compounds were also identified. The enrichment of these terms

545 confirms the assumption that novel chloroplast-targeted proteins likely contribute to species-

546 specific biochemistry. However, the high enrichment of terms associated with transcriptional

547 processes and protein binding suggests that an equally important function of novel plastid-

548 targeted genes may be in the regulation of plastid gene expression and protein function.

549

550 Intraspecific mechanism of NPTP evolution

\section{Mechanisms of NPTP Evolution in the Arabidopsis pangenome}

552 The analysis workflow was applied to Arabidopsis pan-genome to test whether the NPTP

553 evolutionary trends observed across the multi-genome dataset hold true at smaller evolutionary

554 scales. The Arabidopsis1001 Project (Cao et al., 2011; Joshi et al., 2012; Alonso-Blanco et al.,

555 2016) has described protein allelic variants for 35,176 genes of 256 diverse $A$. thaliana

556 accessions. Of these initial gene groups, 928 contained isoforms with subcellular prediction to

557 both plastid and non-plastid targets. A monophyletic plastid transit peptide origin was found in

558180 of these. Surprisingly, only a single deletion event was found in AT3G06180.1, and no

559 insertion events were detected. A second gene, AT3G13820.1, had a C-terminal 4-residue

560 deletion that altered the predicted targeting of the protein, but this was due to a nonsense

561 mutation in the predicted NPTP which would disrupt the downstream domains of the original

562 protein. All remaining mutations were caused by residue substitutions (Figure 7A). While these

563 results are significantly different from what was observed in the multi-genome dataset, it should

564 be stressed that the Arabidopsis1001 data contains only allelic variants and ignores gene

565 duplication events. Only 1.34 substitutions occurred on average between each pair of sequences

566 observed in the current experiment, and single substitutions were responsible for $71 \%$ of the

567 predicted NPTPs. This is in line with the average of 439,000 SNPs, or roughly 1 SNP per $1 \mathrm{~kb}$,

568 detected between any two Arabidopsis accession genomes (Alonso-Blanco et al., 2016). 
569 Substitutions were heavily concentrated in the proximal third of the putative transit peptide: 126

570 substitutions occurred in the first 20 positions, followed by 90 in positions $21-40$, and only 37 in

571 positions 41-60 (Figure 7B). Nearly 75\% of the substitutions were nonconservative, with

572 nonpolar to polar transitions accounting for over $21 \%$ of such substitutions. Basic to polar

573 substitutions occurred $15.3 \%$ of the time, followed by acidic to nonpolar (9.5\%), aromatic to

574 polar (8.5\%), and nonpolar to basic (7.9\%) (Figure 7C). Overall, this pattern follows what had

575 been observed for transit peptide composition (Figures 1 and 2), with enrichment in serine,

576 proline, alanine, and arginine, and depletion of acidic, aromatic, and long polar amino acids.

577

578 Figure 7: NPTP Mutation Sources and Characteristics in Arabidopsis1001. (A) The data for

579 Arabidopsis1001 showed only one instance of an internal deletion and one instance of a C-

580 terminal deletion causing a difference in targeting prediction, while the remaining instances were

581 caused by substitutions. (B) A significant negative trend in substitution frequency was observed

582 for Arabidopsis 1001 sequences, with up to 4\% of substitutions occurring at positions in the

583 proximal end, and $0-1 \%$ of substitutions occurring at positions in the distal end. (C) significant

584 increases in cysteine, asparagine, and serine were observed in the substitutions, while aspartic

585 acid, glutamic acid, and leucine had significant decreases.

586

587 Distribution of NPTPs was examined across different taxonomic sub-groups of Arabidopsis

588 representing various geographical regions and environments. This was performed to test the

589 hypothesis that there will be a variation in the occurrence of NPTPs in different environments.

590 The admixed, central European, German, and Italian/Balkan/Caucasian groups were found to

591 have the greatest number of NPTPs, which follows with these groups representing a greater

592 fraction of accessions (Figure 8A). The admixed group, which contains intermediate

593 characteristics between two or more distinct taxonomic groups, had the largest representation of

594 NPTPs overall. In keeping with admixed populations sharing genetics with more distinct

595 taxonomic groups, many NPTPs were shared between a mixture of accessions. Most NPTP

596 clusters contained only a single accession with a predicted novel plastid-targeted protein, but a

597 small number of clusters skewed this trend, with one cluster containing 38 accessions sharing the

598 same NPTP. Thus, many NPTPs in the admixed accessions likely originate from a neighboring 
599 population from which the plastid-targeted allele has propagated into adjacent geographic 600 regions.

601

602 Upon normalizing diversity per accession, relict accessions native to the Iberian Peninsula were 603 found to be the most diverse, at an average of 10 NPTPs for each line (Figure 8B). Non-relict 604 Spanish accessions and accessions from the Italian/Balkan/Caucasus group were also diverse, but 605 in terms of average diversity, they were closer to other groups than to the relict group.

606 Pangenome analysis suggested that these taxonomic groups are more variable because they 607 survived the last glaciation period, while the other taxonomic groups developed after the species 608 propagated outward from glacial refuges (see Figure 8C for geographic representation)(Alonso609 Blanco et al., 2016). Upon normalizing diversity per accession, they were found to be the most 610 diverse NPTPs (Figure 8B). Non-relict Spanish accessions and accessions from the 611 Italian/Balkan/Caucasus group were also diverse, but in terms of average diversity, they were 612 closer to other groups than to the relict group that spread out (see Figure 8C for geographic 613 representation). In contrast, the Asian accessions at the easternmost edge of the Arabidopsis 614 native range are the least diverse, with the fewest NPTPs per accession. Please refer to 615 Supplemental File 4 for the analysis output.

616

617 Figure 8: Geographic Distribution of NPTPs in Arabidopsis1001 Accessions. Taxonomic 618 groups were referenced according to the Arabidopsis1001 Proteomes project, and the number of 619 NPTP's for each accession were added to the respective taxonomic group. The admixed group, 620 including the Columbia-0 accession, accounted for the most NPTP's (A) but was overall one of 621 the least diverse taxonomic groups. Relict, Italian/Balkan/Caucasus, and Spanish accessions 622 contained the most NPTPs per genotype, while Asian, Swedish, Germanic, and Central European 623 accessions contained the fewest (B). Geographic distribution is indicated in (C), where shaded 624 circular areas are indicative of magnitude. Taxonomic groups are color-coded, according to Joshi 625 et al., 2012. The map used in this figure was obtained from 626 https://www.freeworldmaps.net/about.html (C) https://www.freeworldmaps.net/).

627

628 GO enrichment of NPTPs in the Arabidopsis1001 dataset demonstrated a significant 629 underrepresentation ( $\mathrm{p}<0.05$ ) of membrane-bound organelle (GO:0043227; GO:0043231), 
630 organic substance metabolic process (GO:0071704), and primary metabolic process

631 (GO:0044238), which is expected for genes with variable plastid targeting (Table 5). In contrast,

632 the majority of overrepresented terms were involved in secondary metabolic and redox

633 processes, such as flavin-containing compound metabolism and biosynthesis (GO:0042726;

634 GO:0042727), adenylyltransferase activity (GO:0003919; GO:0070566) glycosyl or hexosyl

635 transferase activity (GO:0016757; GO:0016758), and glycerol ether metabolism (GO:0006662).

636 Additionally, processes involved in G-coupled receptor signaling (GO:0007205; GO:0007186)

637 were overrepresented.

638

639 Mechanisms of NPTP Evolution in the Brachypodium Pan Genome

640 Pan-genome sequencing in many species has revealed significant variation in duplicated and 641 expendable genes: in some cases, the core genes represent a minority of the total genes for a 642 given species. The BrachyPan project for Brachypodium distachyon conducted deep re643 sequencing of 54 accessions of $B$. distachyon to characterize presence/absence variants (PAVs) 644 and copy number variants (CVs) in addition to allelic and isoform variants (Gordon et al., 2017).

645 Predicted proteomes of 56 different $B$. distachyon ecotypes including two internal Bd21-3 646 controls were accessed from BrachyPan (https://brachypan.jgi.doe.gov/) and sequences were 647 arranged into clusters according to a reference matrix file provided by Dr. John Vogel, DOE, 648 USA (Personal communication).

649

650

8,990 orthologous pan-gene clusters that had at least one predicted plastid-targeted gene and one 651 alternatively targeted gene were detected using the same methods as for Arabidopsis1001.

652 RaxML was performed on 7,551 of the candidate gene clusters. The most recent common 653 ancestor was likely plastid-targeted in 4,616 of these clusters, indicated by a plastid transit 654 peptide at the root of the phylogenetic tree. 2,272 clusters were found to have a monophyletic 655 transit peptide origin, and were investigated for mechanisms of transit peptide acquisition 656

657 As with Arabidopsis1001, transit peptide loss was more prevalent than transit peptide gain. This 658 pattern has been observed previously, where the loss of signal peptides prevailed over gains by a 659 factor of almost 4-fold (Hönigschmid et al., 2018). This ratio held true for both Arabidopsis1001 660 and BrachyPan. For clusters representing transit peptide acquisitions, gene variants were much 
661 more divergent than the Arabidopsis1001 clusters and more closely mirrored the multi-genome 662 dataset (Figure 9). An average of 12.7 substitutions were found in each divergent pair of 663 sequences, $69.4 \%$ of which were non-conservative. Length variants were also common, with an 664 average of 0.80 insertions and 1.08 deletions occurring in each alignment. Despite a large 665 number of substitutions per aligned pair, substitutions were the dominant means of transit 666 peptide acquisition in only $28.3 \%$ of clusters, while insertions and deletions were responsible for 667 the remaining $71.7 \%$. Alternative start sites resulting in an insertion for the plastid-targeted 668 protein were found in $20.1 \%$ of cases, while alternative start sites resulting in a deletion were 669 found in $11.4 \%$ of cases (Figure 9A).

670

671 Insertions and deletions that did not align with an in-frame methionine and therefore did not 672 represent alternative start sites accounted for $19.6 \%$ and $20.6 \%$ of cases, respectively. The most 673 frequent size of both insertions and deletions were those that covered the full 60 amino acids of 674 the putative transit peptide. Of the remainder, the most abundant size range in both cases was 675 between 1-5 residues, and frequency declined as gap size increased. More substitutions were 676 found at the beginning of the aligned sequence, although the difference was not nearly as 677 pronounced as observed in Arabidopsis: $38.2 \%$ of substitutions were found in the first 20 678 positions, $34.2 \%$ between positions $21-40$, and $27.6 \%$ between positions $41-60$ (Figure 9B). 679

Large increases in proline, arginine, serine, and threonine were observed along with decreases in 681 aspartic acid, glutamic acid, glycine, leucine, valine, and tyrosine, although the magnitude of 682 these changes was not nearly as drastic as observed for Arabidopsis1001 sequences (Figure 9C). Most residues were not substantially different between substitutions and indels, although it is interesting to note that both serine and threonine were somewhat more likely to be caused by substitutions: the net change of serine was $+4.4 \%$ for (insertions/deletions) and $+6.5 \%$ for substitutions, while the net changes in threonine were $+1.0 \%$ and $+2.2 \%$, respectively (Figure 9D). Introductions of proline were conversely more likely to occur due to insertions or deletions 688 $(+6.4 \%)$ compared to residue substitutions $(+5.1 \%)$. All other amino acids differed by a less 689 significant margin between mutational modes. 
691 Figure 9: NPTP Mutation Sources and Characteristics in BrachyPan. (A) 28.3\% of transit

692 peptide acquisitions were explained by substitutions, followed by deletions, upstream alternative 693 start sites, and deletions. (B) Substitution frequency was greatest at the proximal end and 694 decreased linearly to the distal end. (C) the net change in residue composition favored increases 695 in proline, arginine, serine, and threonine in transit peptides, while aspartic and glutamic acids, 696 glycine, and leucine had $2 \%$ or greater decreases. (D) Insertions or deletions which covered the 697 entirety of the transit peptide region were most abundant, indicating possible exon swapping. Of 698 the remaining elements, smaller elements were most abundant and decreased in frequency with 699 increasing size.

700

Among all BrachyPan clusters, less than 5\% of variant sequence pairs were from the same 702 accession, indicating that variants caused by either isoforms or gene duplications within a single

703

704

705

706

707

708

709

710

711

712

713

714

715

716

717

718

719

720

721

accession are rare. The frequency of NPTPs correlates with the population size of each taxonomic group reported previously (Gordon et al., 2017) (Figure 10A). When normalized per accession, the extremely-delayed flowering (EDF+) accessions had nearly twice the NPTP diversity as the Turkish $(\mathrm{T}+)$ and Spanish $(\mathrm{S}+)$ accessions (Figure 10B). The geographic distribution of accession diversity clearly shows that the most diverse accessions are generally found in or near Turkey (Figure 10C). Even the reference Bd21-3 genome, which was collected in Iraq, has a greater number of NPTPs than many of the Spanish accessions. These results indicate that NPTP evolution followed a similar pattern to the Arabidopsis1001 dataset, and further implies that novel plastid-targeted proteins evolve in response to environmental pressures followed by natural selection. Please refer to Supplemental File 5 for the analysis output.

Figure 10: Geographic Distribution of NPTPs in BrachyPan Accessions. The Turkish $(\mathrm{T}+)$ taxonomic group had the most NPTPs in absolute numbers (A), but when measured per accession, the extremely-delayed flowering taxonomic group (EDF+) was nearly twice as divergent (B). Geographic distribution of these lines is indicated in (C), where the length of each bar corresponds the number of NPTPs for each labeled accession. Taxonomic groups are colorcoded according to Gordon et al., 2017. The map used in this figure was obtained from https://www.freeworldmaps.net/about.html (@ https://www.freeworldmaps.net/).

Peer] reviewing PDF | (2019:12:43773:1:2:NEW 5 Jul 2020) 
722 Within the Brachypodium pan-genome, clusters are categorized into "core" (56 genomes;

723 100\%), "softcore" (53-55 genomes; 95-98\%), "shell” (3-52 lines; 5-94\%), and "cloud" (1-2

724 genomes; 2-5\%) categories (Gordon et al., 2017). Over half (56.6\%) of NPTPs occurred in core

725 clusters, $25.2 \%$ occurred in softcore clusters, $17.9 \%$ occurred in shell clusters, and cloud clusters

726 accounted for only 2 NPTPs, or $0.2 \%$ of the total (Figure 11 ).

727

728 Figure 11: Gene Conservation of NPTPs in BrachyPan. "Core" genes are those shared by all

72956 accessions, "Softcore" genes are shared by 53-55 accessions, "Shell” genes are shared by 3-

73052 accessions, and "Cloud" genes are found in 1-2 accessions. While the largest group of

731 orthologous genes was the "Shell" category in Gordon et al., the present work found that "Core"

732 and "Softcore" categories accounted for the most NPTPs. Categories are color-coded according

733 to Gordon et al. (2017).

734

735 Previously published GO annotation information (Gordon et al., 2017) was converted into GO

736 slim categories in BLAST2GO and compared to the Bd21-3 reference genome to find under- and

737 over-represented terms (Table 6). Using p-value $<0.05$ as a significance threshold, significant

738 underrepresentation of cytoplasmic and ribosomal terms was found for cellular component

739 ontologies, while structural molecule activity, ribosomal components, and cyclic compound

740 binding terms were underrepresented for molecular function ontologies. Overrepresented terms

741 involved in biological processes included nitrogen metabolism, cell wall organization, and lipid

742 metabolism, suggesting that secondary metabolic processes are significantly more likely to have

743 differential targeting. Terms of the molecular function ontology included ion binding, kinase

744 activity, transferase activity, and catalytic activity. Overrepresented cellular component ontology

745 terms were somewhat scattered, reflecting the selection of differentially-targeted genes.

746

747 Interestingly, several terms associated with inclusion bodies (GO:0090083, GO:0090084,

748 GO:0070841) were overrepresented. Inclusion bodies are associated with viruses, so the

749 enrichment of these terms suggests that not all NPTPs may be endogenous proteins. Sequences

750 from pathogens and endosymbionts are common contaminants of high-throughput sequencing

751 data, and eukaryotic genomes often have dormant retroviral elements scattered throughout their

752 genomes [e.g., (Sabot \& Schulman, 2006)]. Although these sequences may at first glance appear 
753 to be false positives, effector proteins from multiple pathogenic species have been observed to

754 translocate to the chloroplast (Dodds \& Rathjen, 2010; Win et al., 2012). For instance,

755 bioinformatic analysis of Pseudomonas syringae effector proteins predicts many to be

756 chloroplast-targeted (Guttman et al., 2002), and at least four have been confirmed in vivo

757 (Jelenska et al., 2007; Rodríguez-Herva et al., 2012; Li et al., 2014). Plastid-targeted effectors

758 also appear to be highly abundant in rust fungi [reviewed in (Lorrain, Petre \& Duplessis, 2018)].

759 Effector proteins from both bacteria and fungi suppress hypersensitive responses by targeting

760 protein folding, salicylic and jasmonic acid production, photosystem II, and ROS signaling

761 pathways. Furthermore, coat proteins of cucumber necrosis virus and Lolium lentivirus have also

762 been described to have plastid localization, which may promote virus coat disassembly as well as

763 target host immune pathways (Hui, Xiang \& Rochon, 2010; Vaira et al., 2018).

764

765 Transposon-based origin of NPTPs

766 Transposable element sequences for all Viridiplantae species were downloaded from REPBASE

767 release 23.03 ("RepBase"). All possible open reading frames of at least $300 \mathrm{bp}$ were mined from

768 this dataset, translated to protein sequences, and analyzed with TargetP and Localizer. A total of

76919,848 sequences with a consensus plastid targeting prediction were extracted and collected into

770 a BLAST database for analysis against potential evolutionarily emergent plastid transit peptides.

771 Each pair of diverged sequences was compared to this database of transposon sequences to see if

772 the same transposon sequence was a match in both or unique to one sequence.

773

774 Using an e-value cutoff of $\mathrm{e}^{*} 10^{-5}$, transposons were not found to be a significant source of transit

775 peptide acquisition. No examples were found in the Arabidopsis1001 dataset, although this is

776 unsurprising given that almost all pairs differed by only 1-2 substitutions. In BrachyPan, 33

777 potential candidates were identified, while in the multi-genome dataset, a total of 12 candidates

778 were found. However, only a small fraction of these candidates consisted of high-scoring

779 matches covering a majority of the transit peptide, so many initial hits were the result of random

780 sequence alignment. Although transposons may donate functional transit peptides in a minority

781 of cases, the evidence suggests that they are insignificant in the evolution of the plastid

782 proteome. 


\section{Gaps in Orthologous Protein Prediction}

785 It is likely that the total number of NPTPs has been underestimated in all datasets because

786 relatively stringent criteria were implemented in this study. In the Arabidopsis1001 dataset,

787 sequences seldom differ by more than a few residues throughout the whole gene sequence, and

788 as a result, the phylogenetic trees have extremely short branch lengths. Many poorly-resolved

789 trees were likely discarded due to this problem alone.

790

791 In contrast, the BrachyPan and multi-genome gene clusters represent broader orthologous or

792 homologous gene families and are far more likely to have relatively divergent branches with

793 nascent plastid transit peptides. Yet, the inclusion of broader sequence variants also introduces

794 the potential for error. In BrachyPan, many in-paralogs had poor sequence alignment and are

795 likely to be unrelated, while in the multi-genome analysis, most of the smaller clusters were

796 orthologous, but larger clusters often included paralogs. However, these trees were resolved with

797 maximum likelihood methods, poorly aligned or nonhomologous sequences are unlikely to affect

798 the analysis of these clusters.

799 Even so, many larger clusters in which plastid targeting arose independently in multiple

800 paralogs were rejected. In these cases, independently evolving transit peptides would require

801 more stringent clustering methods to resolve individual groups. Finally, the prediction approach

802 using TargetP 1.1 and Localizer achieves excellent correlation with experimentally validated

803 results, but has a significant sensitivity gap which may underrepresent NPTPs or incorrectly

804 predict the exact point of subcellular targeting divergence.

805 In addition to the above-mentioned limitations, there are some generic caveats that apply

806 to any such predictive genome-scale analyses. These include variability in the sequencing,

807 assembly and annotation of the genome, prediction of gene models particularly related to the

808 targeting region of the gene, and the limited spatio-temporal characterization of the

809 transcriptomes. Despite these constraints, differences in gene modeling were accounted for by

810 discarding all orthologous clusters lacking at least three species as best as possible. A majority of

811 gene sequences analyzed in this work were supported by transcriptomics evidence for each

812 genome, although the prediction of the 5' start site can be variable. Within the pan-genomes,

813 predicted transcripts and proteins were generated using a uniform set of models and algorithms,

814 which should mitigate some of the caveats. This study therefore provides an initial predictive 
815 framework at best, which will serve as an initial reference. It warrants an in-depth spatiotemporal

816 study of plastid proteomes via transcriptomics or more aptly in combination with high

817 throughput proteomics methods. Follow up wet-lab experimentation will unravel the diversity of

818 the plastid proteome in specific tissues or conditions as well as across the plant kingdom, and

819 validate or correct the localization predictions presented in this study.

820

\section{Conclusions}

822 Gain and loss of plastid transit peptides yield subcellular relocalization of the proteins

823 they chaperone, leading to changes in the diversity and function of the plastid proteome. This

824 study describes that this phenomenon, despite the caveats noted in the preceding section, is

825 widespread and likely responsible for significant phenotypic changes. The primary sequence

826 composition of monocot and eudicot transit peptides was surprisingly divergent, possibly due to

827 differences in the composition of the TIC translocon at the inner plastid envelope. However, for

828 both monocots and dicots the data supported the hypothesis that transit peptides may evolve via

829 simple substitutions, insertions and deletions, or alternative start sites.

830 It was observed that gain of transit peptides occurs regularly both across diverse genera

831 and within pan-genomes. However, transit peptide loss occurred roughly four times more

832 frequently than the transit peptide gain within orthologous protein clusters of both the

833 Arabidopsis and Brachypodium pan-genomes. Small insertions and deletions were determined to

834 be the dominant form of novel transit peptide evolution, followed by residue substitutions. A

835 majority of indel events represent probable alternative start sites, but internal indels and

836 alternative splicing were also major factors equaling or surpassing residue substitutions in

837 importance. Finally, it was found that gene duplications and alternative protein isoforms are

838 more important factors in the evolution of novel plastid-targeted proteins than allelic variants.

839 Based on GO enrichment, it was apparent that plastid localization variants across

840 multiple species were related to secondary metabolism, transcriptional regulation, and protein

841 regulation. Since plastids are critical for various key metabolic functions, a better understanding

842 of the unique plastid-targeted proteins could reveal important gene candidates for improving

843 yield, nutrient content, environmental stress tolerance, and production of valuable medicinal or

844 aromatic compounds. The outcome of these analyses has established a foundational collection of

845 candidate proteins for confirming localization and functional validation in vivo. 
It could be concluded that plastid-targeting peptides continue to be acquired or lost in

847 wild populations. As the attendant environment changes, proteins experiencing subcellular

848 relocalization may position the subpopulations at a competitive advantage.

\section{Authors' contributions}

$850 \mathrm{RC}$ and $\mathrm{AD}$ designed the study. RC performed localization prediction, gene clustering, and data

851 analysis. EHR provided phylogenetics expertise and advice. GN wrote scripts for automating

852 phylogenetics workflows and performed phylogenetic comparisons. AD and EHR supervised the

853 study. SLH performed GO enrichment and annotation analyses. RC and AD prepared the

854 manuscript. All authors read and approved the manuscript. The authors declare no conflict of

855 interest.

856

\section{Availability of data and materials}

858 "The datasets supporting the conclusions of this article are included within the article and its

859 Supplemental files 1-6. Perl scripts used in the organization of data and execution of protein

860 clustering are available at Sourceforge under the Project Name "Plastid Variation" and the

861 homepage https://sourceforge.net/p/plastid-variation. (Supplemental File 6)

862 Operating System(s): Platform Independent

863 Programming Language: Perl

864 Other Requirements: TargetP v.1.1, Localizer v.1.0.2, BLAST v.2.3.9+ command line

865 executable, UCLUST v.9.2.64_win32, RAxML v.8.2.31, MUSCLE v.3.8.31, MAFFT v. 7.407,

866 Phyutility v2.2.6, FastTree 2.1.10.

867 License: open source

868 Restrictions for use by non-academics: no restrictions.

869

870

\section{Acknowledgments}

871 Work in the Dhingra lab was supported by Washington State University Agriculture Center

872 Research Hatch Grant WNP00011 to AD. RC and SLH acknowledge the support received from

873 the National Institutes of Health/National Institute of General Medical Sciences through an

874 institutional training grant award T32-GM008336. The contents of this work are solely the

875 responsibility of the authors and do not necessarily represent the official views of the NIGMS or 
876 NIH. SLH acknowledges the support received from ARCS Seattle Chapter. The authors thank

877 the three anonymous reviewers whose comments and suggestions helped improve and clarify this

878 manuscript.

879

880

\section{References}

881

1001 Proteomes.

882

Ajjawi I, Lu Y, Savage LJ, Bell SM, Last RL. 2010. Large-Scale Reverse Genetics in Arabidopsis: Case Studies from the Chloroplast 2010 Project. Plant Physiology 152:529- 
907

908

909

910

911

912

913

914

915

916

917

918

919

920

921

922

923

924

925

926

927

928

929

930

931

932

933

934

935

936

937

11:M111.015131. DOI: 10.1074/mcp.M111.015131.

Bölter B, Soll J. 2016. Once upon a Time - Chloroplast Protein Import Research from Infancy to Future Challenges. Molecular Plant 9:798-812. DOI: 10.1016/j.molp.2016.04.014.

Bölter B, Soll J. 2017. Ycf1/Tic214 Is Not Essential for the Accumulation of Plastid Proteins. Molecular Plant 10:219-221. DOI: 10.1016/j.molp.2016.10.012.

BrachyPan.

Brillouet JM, Romieu C, Schoefs B, Solymosi K, Cheynier V, Fulcrand H, Verdeil JL, Conéjéro G. 2013. The tannosome is an organelle forming condensed tannins in the chlorophyllous organs of Tracheophyta. Annals of Botany 112:1003-1014. DOI: 10.1093/aob/mct168.

Brillouet JM, Verdeil JL, Odoux E, Lartaud M, Grisoni M, Conéjéro G. 2014. Phenol homeostasis is ensured in vanilla fruit by storage under solid form in a new chloroplastderived organelle, the phenyloplast. Journal of Experimental Botany 65:2427-2435. DOI: $10.1093 / \mathrm{jxb} / \mathrm{eru} 126$.

Bruce BD. 2000. Chloroplast transit peptides: Structure, function and evolution. Trends in Cell Biology 10:440-447. DOI: 10.1016/S0962-8924(00)01833-X.

Bruce BD. 2001. The paradox of plastid transit peptides: Conservation of function despite divergence in primary structure. Biochimica et Biophysica Acta-Molecular Cell Research 1541:2-21. DOI: 10.1016/S0167-4889(01)00149-5.

Byun-McKay SA, Geeta R. 2007. Protein subcellular relocalization: a new perspective on the origin of novel genes. Trends in Ecology and Evolution 22:338-344. DOI: 10.1016/j.tree.2007.05.002.

Cao J, Schneeberger K, Ossowski S, Günther T, Bender S, Fitz J, Koenig D, Lanz C, Stegle O, Lippert C, Wang X, Ott F, Müller J, Alonso-Blanco C, Borgwardt K, Schmid KJ, Weigel D. 2011. Whole-genome sequencing of multiple Arabidopsis thaliana populations. Nature Genetics 43:956-963. DOI: 10.1038/ng.911.

Carrie C, Giraud E, Whelan J. 2009. Protein transport in organelles: Dual targeting of proteins to mitochondria and chloroplasts. FEBS Journal 276:1187-1195. DOI: 10.1111/j.17424658.2009.06876.x.

Cavalier-Smith T. 1987. The Simultaneous Symbiotic Origin of Mitochondria, Chloroplasts, and Microbodies. Annals of the New York Academy of Sciences 503:55-71. DOI: 10.1111/j.1749-6632.1987.tb40597.x.

Peer) reviewing PDF | (2019:12:43773:1:2:NEW 5 Jul 2020) 
938 Celedon JM, Cline K. 2013. Intra-plastid protein trafficking: How plant cells adapted prokaryotic 939 mechanisms to the eukaryotic condition. Biochimica et Biophysica Acta - Molecular Cell $940 \quad$ Research 1833:341-351. DOI: 10.1016/j.bbamcr.2012.06.028.

941 Chotewutmontri P, Bruce BD. 2015. Non-native, N-terminal Hsp70 Molecular Motor942 recognition Elements in Transit Peptides Support Plastid Protein Translocation. Journal of 943 Biological Chemistry 290:7602-7621. DOI: 10.1074/jbc.M114.633586.

944 Chotewutmontri P, Reddick LE, McWilliams DR, Campbell IM, Bruce BD. 2012. Differential 945 Transit Peptide Recognition during Preprotein Binding and Translocation into Flowering 946 Plant Plastids. The Plant Cell 24:3040-3059. DOI: 10.1105/tpc.112.098327.

947 Christian RW, Hewitt SL, Roalson EH, Dhingra A. 2020. Genome-Scale Characterization of 948 Predicted Plastid-Targeted Proteomes in Higher Plants. Scientific Reports 10:8281. DOI: 10.1038/s41598-020-64670-5.

950

951

952

953

954

Comai L, Larson-Kelly N, Kiser J, Mau CJD, Pokalsky AR, Shewmaker CK, Mcbride K, Jones A, Stalker DM. 1988. Chloroplast Transport of a Ribulose Bisphosphate Carboxylase Small

955

956

957

958

959

960

961

962

963

964

965

966

967

968
Subunit-5-Enolpyruvyl 3-Phosphoshikimate Synthase Chimeric Protein Requires Part of the Mature Small Subunit in Addition to the Transit Peptide. The Journal of Biological Chemistry 263:15104-15109.

Conesa A, Götz S. 2008. Blast2GO: A comprehensive suite for functional analysis in plant genomics. International Journal of Plant Genomics 2008. DOI: 10.1155/2008/619832.

Conesa A, Götz S, García-Gómez JM, Terol J, Talón M, Robles M. 2005. Blast2GO: A universal tool for annotation, visualization and analysis in functional genomics research. Bioinformatics 21:3674-3676. DOI: 10.1093/bioinformatics/bti610.

Davis MJ, Hanson KA, Clark F, Fink JL, Zhang F, Kasukawa T, Kai C, Kawai J, Carninci P, Hayashizaki Y, Teasdale RD. 2006. Differential use of signal peptides and membrane domains is a common occurrence in the protein output of transcriptional units. PLoS Genetics 2:554-563. DOI: 10.1371/journal.pgen.0020046.

Dodds PN, Rathjen JP. 2010. Plant immunity: towards an integrated view of plant-pathogen interactions. Nature Reviews Genetics 11:539-548. DOI: 10.1038/nrg2812.

Edgar RC. 2010. Search and clustering orders of magnitude faster than BLAST. Bioinformatics 26:2460-2461. DOI: 10.1093/bioinformatics/btq461.

Emanuelsson O, Brunak S, von Heijne G, Nielsen H. 2007. Locating proteins in the cell using 
969

970

971

972

973

974

975

976

977

978

979

980

981

982

983

984

985

986

987

988

989

990

991

992

993

994

995

996

997

998

999

TargetP, SignalP and related tools. Nature Protocols 2:953-71. DOI:

10.1038/nprot.2007.131.

Emanuelsson O, Nielsen H, Brunak S, von Heijne G. 2000. Predicting Subcellular Localization of Proteins Based on their N-terminal Amino Acid Sequence. Journal of Molecular Biology 300:1005-1016. DOI: 10.1006/jmbi.2000.3903.

Ferro M, Brugière S, Salvi D, Seigneurin-Berny D, Court M, Moyet L, Ramus C, Miras S, Mellal M, Le Gall S, Kieffer-Jaquinod S, Bruley C, Garin J, Joyard J, Masselon C, Rolland N. 2010. AT_CHLORO, a Comprehensive Chloroplast Proteome Database with Subplastidial Localization and Curated Information on Envelope Proteins. Molecular \& Cellular Proteomics 9:1063-1084. DOI: 10.1074/mcp.M900325-MCP200.

Gordon SP, Contreras-Moreira B, Woods DP, Des Marais DL, Burgess D, Shu S, Stritt C, Roulin AC, Schackwitz W, Tyler L, Martin J, Lipzen A, Dochy N, Phillips J, Barry K, Geuten K, Budak H, Juenger TE, Amasino R, Caicedo AL, Goodstein D, Davidson P, Mur LAJ, Figueroa M, Freeling M, Catalan P, Vogel JP. 2017. Extensive gene content variation in the Brachypodium distachyon pan-genome correlates with population structure. Nature Communications 8. DOI: 10.1038/s41467-017-02292-8.

Guo L, Liu CM. 2015. A single-nucleotide exon found in Arabidopsis. Scientific Reports 5:1-5. DOI: $10.1038 /$ srep 18087.

Gusberti M, Gessler C, Broggini GAL. 2013. RNA-seq analysis reveals candidate genes for ontogenic resistance in Malus-Venturia pathosystem. PLOS ONE 8. DOI: 10.1371/journal.pone.0078457.

Guttman DS, Vinatzer BA, Sarkar SF, Ranall M V, Kettler G, Greenberg JT. 2002. A Functional Screen for the Type III ( Hrp ) Secretome of the Plant Pathogen Pseudomonas syringae Linked references are available on JSTOR for this article : Type III ( Hrp ) Secretome of the Plant Pathogen Pseudomonas syringae. Science 295:1722-1726.

Hönigschmid P, Bykova N, Schneider R, Ivankov D, Frishman D. 2018. Evolutionary Interplay between Symbiotic Relationships and Patterns of Signal Peptide Gain and Loss. Genome Biology and Evolution 10:928-938. DOI: 10.1093/gbe/evy049.

Hooper CM, Castleden IR, Aryamanesh N, Jacoby RP, Millar AH. 2015. Finding the subcellular location of barley, wheat, rice and maize proteins: The compendium of crop proteins with annotated locations (cropPAL). Plant and Cell Physiology 57:e9. DOI: 
1000

1001

1002

1003

1004

1005

1006

1007

1008

1009

1010

1011

1012

1013

1014

1015

1016

1017

1018

1019

1020

1021

1022

1023

1024

1025

1026

1027

1028

1029

1030

$10.1093 / \mathrm{pcp} / \mathrm{pcv} 170$.

Hooper CM, Castleden IR, Tanz SK, Aryamanesh N, Millar AH. 2017. SUBA4: The interactive data analysis centre for Arabidopsis subcellular protein locations. Nucleic Acids Research 45:D1064-D1074. DOI: 10.1093/nar/gkw1041.

Huang S, Taylor NL, Whelan J, Millar AH. 2009. Refining the Definition of Plant Mitochondrial Presequences through Analysis of Sorting Signals, N-Terminal Modifications, and Cleavage Motifs. Plant Physiology 150:1272-1285. DOI: 10.1104/pp.109.137885.

Hui E, Xiang Y, Rochon D. 2010. Distinct regions at the N-terminus of the Cucumber necrosis virus coat protein target chloroplasts and mitochondria. Virus research 153:8-19.

Inoue H, Rounds C, Schnell DJ. 2010. The Molecular Basis for Distinct Pathways for Protein Import into Arabidopsis Chloroplasts. The Plant Cell 22:1947-1960. DOI: 10.1105/tpc.110.074328.

Jelenska J, Yao N, Vinatzer BA, Wright CM, Brodsky JL, Greenberg JT. 2007. A J Domain Virulence Effector of Pseudomonas syringae Remodels Host Chloroplasts and Suppresses Defenses. Current Biology 17:499-508. DOI: 10.1016/j.cub.2007.02.028.

Jelic M, Soll J, Schleiff E. 2003. Two Toc34 homologues with different properties. Biochemistry 42:5906-5916. DOI: 10.1021/bi034001q.

Joshi HJ, Christiansen KM, Fitz J, Cao J, Lipzen A, Martin J, Smith-Moritz AM, Pennacchio LA, Schackwitz WS, Weigel D, Heazlewood JL. 2012. 1001 Proteomes: A functional proteomics portal for the Analysis of arabidopsis thaliana accessions. Bioinformatics 28:1303-1306. DOI: 10.1093/bioinformatics/bts133.

Juan J, Armenteros A, Salvatore M, Emanuelsson O, Winther O, Heijne G Von, Elofsson A, Nielsen H. 2019. Detecting sequence signals in targeting peptides using deep learning. 2:114. DOI: $10.26508 / 1$ sa.201900429.

Karlin-Neumann GA, Tobin EM. 1986. Transit peptides of nuclear-encoded chloroplast proteins share a common amino acid framework. The EMBO Journal 5:9-13. DOI: 10.1002/j.14602075.1986.tb04170.x.

Katoh K, Misawa K, Kuma K, Miyata T. 2002. MAFFT: a novel method for rapid multiple sequence alignment based on fast Fourier transform. Nucleic acids research 30:3059-3066. DOI: $10.1093 /$ nar/gkf436.

Katoh K, Standley DM. 2013. MAFFT multiple sequence alignment software version 7: 
1031

1032

1033

1034

1035

1036

1037

1038

1039

1040

1041

1042

1043

1044

1045

1046

1047

1048

1049

1050

1051

1052

1053

1054

1055

1056

1057

1058

1059

1060

1061

Improvements in performance and usability. Molecular Biology and Evolution 30:772-780. DOI: $10.1093 / \mathrm{molbev} / \mathrm{mst} 010$.

Kleffmann T, von Zychlinski A, Russenberger D, Hirsch-Hoffmann M, Gehrig P, Gruissem W, Baginsky S. 2007. Proteome Dynamics during Plastid Differentiation in Rice. Plant Physiology 143:912-923. DOI: 10.1104/pp.106.090738.

Krost C, Petersen R, Lokan S, Brauksiepe B, Braun P, Schmidt ER. 2013. Evaluation of the hormonal state of columnar apple trees (Malus x domestica) based on high throughput gene expression studies. Plant Molecular Biology 81:211-220. DOI: 10.1007/s11103-012-99920 .

Krost C, Petersen R, Schmidt ER. 2012. The transcriptomes of columnar and standard type apple trees (Malus x domestica) - A comparative study. Gene 498:223-230. DOI: 10.1016/j.gene.2012.01.078.

Lee DW, Kim JK, Lee S, Choi S, Kim S, Hwang I. 2008. Arabidopsis Nuclear-Encoded Plastid Transit Peptides Contain Multiple Sequence Subgroups with Distinctive ChloroplastTargeting Sequence Motifs. The Plant Cell 20:1603-1622. DOI: 10.1105/tpc.108.060541.

Li G, Froehlich JE, Elowsky C, Msanne J, Ostosh AC, Zhang C, Awada T, Alfano JR. 2014. Distinct Pseudomonas type-III effectors use a cleavable transit peptide to target chloroplasts. Plant Journal 77:310-321. DOI: 10.1111/tpj.12396.

Li H min, Teng YS. 2013. Transit peptide design and plastid import regulation. Trends in Plant Science 18:360-366. DOI: 10.1016/j.tplants.2013.04.003.

Long M, de Souza SJ, Rosenberg C, Gilbert W. 1996. Exon shuffling and the origin of the mitochondrial targeting function in plant cytochrome $\mathrm{c} 1$ precursor. Proceedings of the National Academy of Sciences 93:7727-7731.

Lorrain C, Petre B, Duplessis S. 2018. Show me the way: rust effector targets in heterologous plant systems. Current Opinion in Microbiology 46:19-25. DOI: 10.1016/j.mib.2018.01.016.

Lu Y, Savage LJ, Larson MD, Wilkerson CG, Last RL. 2011. Chloroplast 2010: A Database for Large-Scale Phenotypic Screening of Arabidopsis Mutants. Plant Physiology 155:15891600. DOI: $10.1104 /$ pp.110.170118.

Mackenzie SA. 2005. Plant organellar protein targeting: A traffic plan still under construction. Trends in Cell Biology 15:548-554. DOI: 10.1016/j.tcb.2005.08.007. 
1062 Martin W. 2010. Evolutionary origins of metabolic compartmentalization in eukaryotes. :847-

1063

1064

1065

1066

1067

1068

1069

1070

1071

1072

1073

1074

1075

1076

1077

1078

1079

1080

1081

1082

1083

1084

1085

1086

1087

1088

1089

1090

1091

1092 855. DOI: $10.1098 /$ rstb.2009.0252.

Martin W, Rujan T, Richly E, Hansen A, Cornelsen S, Lins T, Leister D, Stoebe B, Hasegawa M, Penny D. 2002. Evolutionary analysis of Arabidopsis, cyanobacterial, and chloroplast genomes reveals plastid phylogeny and thousands of cyanobacterial genes in the nucleus. Proceedings of the National Academy of Sciences 99:12246-12251. DOI: 10.1073/pnas. 182432999.

McFadden GI. 1999. Endosymbiosis and evolution of the plant cell. Current Opinion in Plant Biology 2:513-519. DOI: 10.1016/S1369-5266(99)00025-4.

McFadden GI, Van Dooren GG. 2004. Evolution: Red algal genome affirms a common origin of all plastids. Current Biology 14:514-516. DOI: 10.1016/j.cub.2004.06.041.

McKay SAB, Geeta R, Duggan R, Carroll B, McKay SJ. 2009. Missing the subcellular target: a mechanism of eukaryotic gene evolution. In: Evolutionary Biology. Springer, 175-183.

Mcwilliams DR. 2007. Bioinformatic and Proteomic Investigation of Chloroplast Transit Peptide Motifs and Genesis.

Mirarab S, Nguyen N, Guo S, Wang L-S, Kim J, Warnow T. 2015. PASTA: Ultra-Large Multiple Sequence Alignment for Nucleotide and Amino-Acid Sequences. Journal of Computational Biology 22:377-386. DOI: 10.1089/cmb.2014.0156.

Mitschke J, Fuss J, Blum T, Höglund A, Reski R, Kohlbacher O, Rensing SA. 2009. Prediction of dual protein targeting to plant organelles: Methods. New Phytologist 183:224-236. DOI: 10.1111/j.1469-8137.2009.02832.x.

Nakai M. 2015. YCF1: A Green TIC: Response to the de Vries et al. Commentary. The Plant Cell 27:1834-1838. DOI: 10.1105/tpc.15.00363.

Patron NJ, Waller RF. 2007. Transit peptide diversity and divergence: A global analysis of plastid targeting signals. BioEssays 29:1048-1058. DOI: 10.1002/bies.20638.

Peeters N, Small I. 2001. Dual targeting to mitochondria and chloroplasts. Biochimica et Biophysica Acta (BBA) - Molecular Cell Research 1541:54-63. DOI: 10.1016/S01674889(01)00146-X.

Petersen R, Djozgic H, Rieger B, Rapp S, Schmidt ER. 2015. Columnar apple primary roots share some features of the columnar-specific gene expression profile of aerial plant parts as evidenced by RNA-Seq analysis. BMC Plant Biology 15:1-16. DOI: 10.1186/s12870-014- 
1093

1094

1095

1096

1097

1098

1099

1100

1101

1102

1103

1104

1105

1106

1107

1108

1109

1110

1111

1112

1113

1114

1115

1116

1117

1118

1119

1120

1121

1122

1123

0356-6.

Pilon M, Wienk H, Sips W, De Swaaf M, Talboom I, Van’t Hof R, De Korte- Kool G, Demel R, Weisbeek P, De Kruijff B. 1995. Functional domains of the ferredoxin transit sequence involved in chloroplast import. Journal of Biological Chemistry 270:3882-3893. DOI: $10.1074 / \mathrm{jbc} .270 .8 .3882$.

Price MN, Dehal PS, Arkin AP. 2010. FastTree 2 - Approximately maximum-likelihood trees for large alignments. PLoS ONE 5. DOI: 10.1371/journal.pone.0009490.

Pujol C, Maréchal-Drouard L, Duchêne AM. 2007. How Can Organellar Protein N-terminal Sequences Be Dual Targeting Signals? In silico Analysis and Mutagenesis Approach. Journal of Molecular Biology 369:356-367. DOI: 10.1016/j.jmb.2007.03.015.

Quigley F, Martin WF, Cerff R. 1988. Intron conservation across the prokaryote-eukaryote boundary: structure of the nuclear gene for chloroplast glyceraldehyde-3-phosphate dehydrogenase from maize. Proceedings of the National Academy of Sciences 85:26722676. DOI: 10.1073/pnas.85.8.2672.

Rensink WA, Pilon M, Weisbeek P. 1998. Domains of a transit sequence required for in vivo import in Arabidopsis chloroplasts. Plant Physiology 118:691-9. DOI: 10.1104/pp.118.2.691.

Rensink WA, Schnell DJ, Weisbeek PJ. 2000. The transit sequence of ferredoxin contains different domains for translocation across the outer and inner membrane of the chloroplast envelope. Journal of Biological Chemistry 275:10265-10271. DOI: 10.1074/jbc.275.14.10265.

RepBase.

Richardson LG, Jelokhani-Niaraki M, Smith MD. 2009. The acidic domains of the Toc159 chloroplast preprotein receptor family are intrinsically disordered protein domains. $B M C$ Biochemistry 10:10-12. DOI: 10.1186/1471-2091-10-35.

Richardson LG, Small EL, Inoue H, Schnell DJ. 2018. Molecular topology of the transit peptide during chloroplast protein import. The Plant Cell:tpc.00172.2018. DOI: 10.1105/tpc.18.00172.

Richly E, Leister D. 2004. An improved prediction of chloroplast proteins reveals diversities and commonalities in the chloroplast proteomes of Arabidopsis and rice. Gene 329:11-16. DOI: 10.1016/j.gene.2004.01.008. 
1124 Rodríguez-Herva JJ, González-Melendi P, Cuartas-Lanza R, Antúnez-Lamas M, Río-Alvarez I,

1125 Li Z, López-Torrejón G, Díaz I, Del Pozo JC, Chakravarthy S, Collmer A, Rodríguez-

1126 Palenzuela P, López-Solanilla E. 2012. A bacterial cysteine protease effector protein

1127 interferes with photosynthesis to suppress plant innate immune responses. Cellular

1128 Microbiology 14:669-681. DOI: 10.1111/j.1462-5822.2012.01749.x.

1129 Rolland V, Badger MR, Price GD. 2016. Redirecting the Cyanobacterial Bicarbonate

1130 Transporters BicA and SbtA to the Chloroplast Envelope: Soluble and Membrane Cargos

1131 Need Different Chloroplast Targeting Signals in Plants. Frontiers in Plant Science 7:1-19.

1132 DOI: $10.3389 /$ fpls.2016.00185.

1133 Sabot F, Schulman AH. 2006. Parasitism and the retrotransposon life cycle in plants: A

1134 hitchhiker's guide to the genome. Heredity 97:381-388. DOI: 10.1038/sj.hdy.6800903.

1135 Schaeffer SM, Christian R, Castro-Velasquez N, Hyden B, Lynch-Holm V, Dhingra A. 2017.

1136 Comparative ultrastructure of fruit plastids in three genetically diverse genotypes of apple

1137 (Malus $\times$ domestica Borkh.) during development. Plant Cell Reports. DOI:

$1138 \quad 10.1007 / \mathrm{s} 00299-017-2179-\mathrm{z}$.

1139 Schaeffer S, Harper A, Raja R, Jaiswal P, Dhingra A. 2014. Comparative analysis of predicted

1140 plastid-targeted proteomes of sequenced higher plant genomes. PLoS ONE 9:e112870. DOI:

1141 10.1371/journal.pone.0112870.

1142 Shen BR, Zhu CH, Yao Z, Cui LL, Zhang JJ, Yang CW, He ZH, Peng XX. 2017. An optimized

1143 transit peptide for effective targeting of diverse foreign proteins into chloroplasts in rice.

1144 Scientific Reports 7:1-12. DOI: 10.1038/srep46231.

1145 Small I, Wintz H, Akashi K, Mireau H. 1998. Two birds with one stone: genes that encode

1146 products targeted to two or more compartments. Plant Molecular Biology 38:265-277.

1147 DOI: $10.1023 / \mathrm{A}: 1006081903354$.

1148 Smith SA, Dunn CW. 2008. Phyutility: A phyloinformatics tool for trees, alignments and

1149 molecular data. Bioinformatics 24:715-716. DOI: 10.1093/bioinformatics/btm619.

1150 Smith MD, Rounds CM, Wang F, Chen K, Afitlhile M, Schnell DJ. 2004. atToc159 is a selective

1151

1152

1153

transit peptide receptor for the import of nucleus-encoded chloroplast proteins. Journal of Cell Biology 165:323-334. DOI: 10.1083/jcb.200311074.

Soltis DE, Albert VA, Leebens-Mack J, Bell CD, Paterson AH, Zheng C, Sankoff D,

1154

DePamphilis CW, Wall PK, Soltis PS. 2009. Polyploidy and angiosperm diversification. 
1155

1156

1157

1158

1159

1160

1161

1162

1163

1164

1165

1166

1167

1168

1169

1170

1171

1172

1173

1174

1175

1176

1177

1178

1179

1180

1181

1182

1183

1184

1185

American Journal of Botany 96:336-348. DOI: 10.3732/ajb.0800079.

Solymosi K, Keresztes A. 2013. Plastid Structure, Diversification and Interconversions II. Land Plants. Current Chemical Biology 6:187-204. DOI: 10.2174/2212796811206030003.

Sperschneider J, Catanzariti A-M, DeBoer K, Petre B, Gardiner DM, Singh KB, Dodds PN, Taylor JM. 2017. LOCALIZER: subcellular localization prediction of both plant and effector proteins in the plant cell. Scientific Reports 7:44598. DOI: 10.1038/srep44598.

Stamatakis A. 2006. RAxML-VI-HPC: maximum likelihood-based phylogenetic analyses with thousands of taxa and mixed models. Bioinformatics 22:2688-2690. DOI:

10.1093/bioinformatics/btl446.

Stamatakis A. 2014. RAxML version 8: A tool for phylogenetic analysis and post-analysis of large phylogenies. Bioinformatics 30:1312-1313. DOI: 10.1093/bioinformatics/btu033.

Sun Q, Zybailov B, Majeran W, Friso G, Olinares PDB, van Wijk KJ. 2009. PPDB, the Plant Proteomics Database at Cornell. Nucleic Acids Research 37:969-974. DOI: 10.1093/nar/gkn654.

Suzuki JY, Amore TD, Calla B, Palmer NA, Scully ED, Sattler SE, Sarath G, Lichty JS, Myers RY, Keith LM, Matsumoto TK, Geib SM. 2017. Organ-specific transcriptome profiling of metabolic and pigment biosynthesis pathways in the floral ornamental progenitor species Anthurium amnicola Dressler. Scientific Reports 7:1-15. DOI: 10.1038/s41598-017-008082.

Suzuki M, Takahashi S, Kondo T, Dohra H, Ito Y, Kiriiwa Y, Hayashi M, Kamiya S, Kato M, Fujiwara M, Fukao Y, Kobayashi M, Nagata N, Motohashi R. 2015. Plastid proteomic analysis in tomato fruit development. PLoS ONE 10:1-25. DOI: 10.1371/journal.pone.0137266.

Teixeira PF, Glaser E. 2013. Processing peptidases in mitochondria and chloroplasts. Biochimica et Biophysica Acta - Molecular Cell Research 1833:360-370. DOI: 10.1016/j.bbamcr.2012.03.012.

The Arabidopsis Genome Initiative. 2000. Analysis of the genome sequence of the flowering plant Arabidopsis thaliana. Nature 408:796-815. DOI: 10.1038/35048692.

Tonkin CJ, Foth BJ, Ralph S a, Struck N, Cowman AF, McFadden GI. 2008. Evolution of malaria parasite plastid targeting sequences. Proceedings of the National Academy of Sciences 105:4781-4785. DOI: 10.1073/pnas.0707827105. 
1186 Vaira AM, Lim HS, Bauchan G, Gulbronson CJ, Miozzi L, Vinals N, Natilla A, Hammond J.

1187 2018. The interaction of lolium latent virus major coat protein with ankyrin repeat protein $1188 \quad \mathrm{NbANKr}$ redirects it to chloroplasts and modulates virus infection. Journal of General 1189 Virology 99:730-742. DOI: 10.1099/jgv.0.001043.

1190 Van’t Hof R, Demel RA, Keegstra K, Kruijff B De. 1991. Lipid-Peptide Interactions Between 1191 Fragments of the Transit Peptide of Ribulase-1,5-Bisphosphate Carboxylase/Oxygsmase 1192 and Chloroplast Membrane Lipids. EMBO Journal 29:0-4.

1193 Vetter IR, Wittinghofer A. 2001. The Guanine in Switch Three Dimensions. Science 294:12991194

Vibranovski MD, Sakabe NJ, De Souza SJ. 2006. A possible role of exon-shuffling in the evolution of signal peptides of human proteins. FEBS Letters 580:1621-1624. DOI: 10.1016/j.febslet.2006.01.094.

Vitulo N, Forcato C, Carpinelli EC, Telatin A, Campagna D, D’Angelo M, Zimbello R, Corso M, Vannozzi A, Bonghi C, Lucchin M, Valle G. 2014. A deep survey of alternative splicing in grape reveals changes in the splicing machinery related to tissue, stress condition and genotype. BMC Plant Biology 14:20-30. DOI: 10.1186/1471-2229-14-99.

de Vries J, Sousa FL, Bölter B, Soll J, Gould SB. 2015. YCF1: A Green TIC? The Plant Cell 27:1827-1833. DOI: $10.1105 /$ tpc.114.135541.

Wang YQ, Yang Y, Fei Z, Yuan H, Fish T, Thannhauser TW, Mazourek M, Kochian L V., Wang X, Li L. 2013. Proteomic analysis of chromoplasts from six crop species reveals insights into chromoplast function and development. Journal of Experimental Botany 64:949-961. DOI: 10.1093/jxb/ers375.

Wienk HLJ, Wechselberger RW, Czisch M, De Kruijff B. 2000. Structure, dynamics, and insertion of a chloroplast targeting peptide in mixed micelles. Biochemistry 39:8219-8227. DOI: $10.1021 / \mathrm{bi000110i.}$

Williams EJB, Pal C, Hurst LD, Li W-H. 2000. The molecular evolution of signal peptides. Gene 253:313-322.

Win J, Chaparro-Garcia A, Belhaj K, Saunders DGO, Yoshida K, Dong S, Schornack S, Zipfel C, Robatzek S, Hogenhout SA, Kamoun S. 2012. Effector biology of plant-associated organisms: Concepts and perspectives. Cold Spring Harbor Symposia on Quantitative Biology 77:235-247. DOI: 10.1101/sqb.2012.77.015933. 
1217 Zhang XP, Glaser E. 2002. Interaction of plant mitochondrial and chloroplast signal peptides

1218 with the Hsp70 molecular chaperone. Trends in Plant Science 7:14-21. DOI:

$1219 \quad 10.1016 / \mathrm{S} 1360-1385(01) 02180-\mathrm{X}$.

1220 Zybailov B, Rutschow H, Friso G, Rudella A, Emanuelsson O, Sun Q, van Wijk KJ. 2008.

1221 Sorting signals, N-terminal modifications and abundance of the chloroplast proteome. PLoS

1222 ONE 3:e1994. DOI: 10.1371/journal.pone.0001994.

1223 


\section{Table $\mathbf{1}$ (on next page)}

Residue Frequency Bias in Selected Datasets

Three sets of experiments examined residue bias in transit peptide sequences: comparing predicted to experimentally-validated transit peptides (prediction bias), comparing transit peptides to whole proteome sequences (Transit Peptide Bias), and comparing sequences derived from predicted transit peptides or proteins from different taxa (Taxa Bias). For each column, the bias is reported as the percentage change in residue frequency between the subject dataset and the query dataset. Frequency bias was observed for transit peptides of experimentally-validated proteins as compared with whole proteome sequences. Smaller but significant biases were observed when comparing predicted transit peptides to transit peptides validated by mass spectrometry. Finally, major bias was found for several residues when comparing predicted transit peptides of monocot species to transit peptides of either eudicot species or Amborella trichopoda. Minor differences were noted for the whole proteomes of these same taxa, and little difference was observed between transit peptides of eudicot species and Amborella. 
1 Table 1: Residue Frequency Bias in Selected Datasets. Three sets of experiments examined

2 residue bias in transit peptide sequences: comparing predicted to experimentally-validated transit

3 peptides (prediction bias), comparing transit peptides to whole proteome sequences (Transit

4 Peptide Bias), and comparing sequences derived from predicted transit peptides or proteins from

5 different taxa (Taxa Bias). For each column, the bias is reported as the percentage change in

6 residue frequency between the subject dataset and the query dataset. Frequency bias was

7 observed for transit peptides of experimentally-validated proteins as compared with whole

8 proteome sequences. Smaller but significant biases were observed when comparing predicted

9 transit peptides to transit peptides validated by mass spectrometry. Finally, major bias was found

10 for several residues when comparing predicted transit peptides of monocot species to transit

11 peptides of either eudicot species or Amborella trichopoda. Minor differences were noted for the

12 whole proteomes of these same taxa, and little difference was observed between transit peptides

13 of eudicot species and Amborella.

\begin{tabular}{|c|c|c|c|c|c|c|c|}
\hline & Experiment: & Prediction & Transit & \multicolumn{4}{|c|}{ Taxa Bias } \\
\hline & Subject: & $\begin{array}{l}\text { Predicted } \\
\text { cTP }\end{array}$ & $\begin{array}{c}\text { MS- } \\
\text { Validated } \\
\text { cTP }\end{array}$ & $\begin{array}{c}\text { Monocot } \\
\text { Whole } \\
\text { Proteome }\end{array}$ & $\begin{array}{c}\text { Monocot } \\
\text { cTP }\end{array}$ & $\begin{array}{c}\text { Monoco } \\
\text { t cTP }\end{array}$ & $\begin{array}{c}\text { Eudicot } \\
\text { cTP }\end{array}$ \\
\hline Residue & Query: & $\begin{array}{c}\text { MS- } \\
\text { Validated } \\
\text { CcTP }\end{array}$ & $\begin{array}{l}\text { TAIR10 } \\
\text { Proteins }\end{array}$ & $\begin{array}{c}\text { Eudicot } \\
\text { Whole } \\
\text { Proteome }\end{array}$ & $\begin{array}{c}\text { Eudicot } \\
\text { сTP }\end{array}$ & $\begin{array}{c}\text { Amborel } \\
\text { la cTP }\end{array}$ & $\begin{array}{c}\text { Amborella } \\
\text { cTP }\end{array}$ \\
\hline Ala & & 3.4 & 43.4 & 20.1 & 111.6 & 112.1 & 0.2 \\
\hline Cys & & 25.1 & 13.5 & 2.0 & 4.1 & -4.7 & -8.5 \\
\hline Asp & & -45.8 & -68.9 & 1.1 & -2.2 & 5.6 & 8.0 \\
\hline Glu & & -48.1 & -70.3 & -4.5 & -10.6 & -25.2 & -16.3 \\
\hline Phe & & -3.5 & -4.0 & -7.0 & -47.7 & -45.4 & 4.5 \\
\hline Gly & & -20.3 & -30.1 & 6.6 & 55.7 & 37.5 & -11.7 \\
\hline His & & 27.1 & 10.2 & 1.8 & -7.4 & -12.9 & -5.9 \\
\hline Ile & & -22.6 & -37.1 & -7.7 & -51.3 & -51.8 & -1.1 \\
\hline Lys & & -22.1 & -32.4 & -11.4 & -54.8 & -52.0 & 6.3 \\
\hline Leu & & 1.5 & -1.3 & -1.2 & -4.8 & -11.1 & -6.6 \\
\hline Met & & -6.8 & 14.7 & 0.6 & -1.4 & -5.5 & -4.2 \\
\hline Asn & & -3.2 & -26.3 & -11.7 & -62.9 & -61.9 & 2.8 \\
\hline
\end{tabular}




\begin{tabular}{|c|c|c|c|c|c|c|}
\hline \multirow{4}{*}{ Pro } & 42.2 & 100.8 & 7.2 & 44.6 & 30.8 & -9.5 \\
\hline Gln & -6.9 & -24.3 & -3.8 & -26.3 & -25.2 & 1.5 \\
\hline Arg & 13.2 & 51.6 & 11.1 & 55.6 & 57.4 & 1.2 \\
\hline Ser & 25.9 & 76.3 & -4.8 & -23.1 & -17.9 & 6.8 \\
\hline Thr & 7.8 & 25.4 & -2.5 & -25.5 & -16.2 & 12.4 \\
\hline Val & -22.4 & -27.9 & 1.2 & 4.5 & 17.1 & 12.1 \\
\hline Trp & -13.4 & -47.2 & 0.6 & 22.1 & -6.1 & -23.2 \\
\hline Tyr & -43.4 & -63.5 & -2.8 & -37.7 & -41.9 & -6.7 \\
\hline
\end{tabular}

15 


\section{Table 2 (on next page)}

\section{Evolutionary Patterns of Transit Peptides}

RAxML maximum likelihood software was used to resolve phylogenetic relationships of sequences within each candidate cluster, and the distribution of predicted transit peptides in each cluster was analyzed to determine whether the cluster had a single, monophyletic origin of the transit peptide, if multiple origins were detected, if a transit peptide was acquired and then lost, or if the most recent common ancestor of all sequences was likely to be plastidtargeted. Note that multiple scenarios can apply to the same cluster, so numbers do not add to $100 \%$. 
1 Table 2: Evolutionary Patterns of Transit Peptides. RAxML maximum likelihood software

2 was used to resolve phylogenetic relationships of sequences within each candidate cluster, and

3 the distribution of predicted transit peptides in each cluster was analyzed to determine whether

4 the cluster had a single, monophyletic origin of the transit peptide, if multiple origins were

5 detected, if a transit peptide was acquired and then lost, or if the most recent common ancestor of

6 all sequences was likely to be plastid-targeted. Note that multiple scenarios can apply to the same

7 cluster, so numbers do not add to $100 \%$.

\begin{tabular}{|l|c|c|c|c|c|}
\hline \multicolumn{1}{|c|}{ Dataset } & $\begin{array}{c}\text { Candidate } \\
\text { Clusters }\end{array}$ & $\begin{array}{c}\text { Polyphyletic } \\
\text { Clusters }\end{array}$ & $\begin{array}{c}\text { Rooted/Basal } \\
\text { Clusters }\end{array}$ & $\begin{array}{c}\text { Gain/Loss } \\
\text { Clusters }\end{array}$ & $\begin{array}{c}\text { Monophyletic } \\
\text { Clusters }\end{array}$ \\
\hline Arabidopsis1001 & 928 & 99 & 527 & 6 & 180 \\
\hline BrachyPan & 7,551 & 1,616 & 4,616 & 116 & 2,272 \\
\hline $\begin{array}{l}\text { Multi-Genome-RBH } \\
\text { only }\end{array}$ & 618 & 15 & 108 & 2 & 430 \\
\hline $\begin{array}{l}\text { Multi-Genome- } \\
\text { UCLUST only }\end{array}$ & 1,443 & 38 & 293 & 11 & 1,061 \\
\hline $\begin{array}{l}\text { Multi-Genome- } \\
\text { Consensus }\end{array}$ & 1,328 & 44 & 180 & 13 & 1,101 \\
\hline
\end{tabular}

8 


\section{Table 3 (on next page)}

Sources of Transit Peptide Evolution by Dataset

For each cluster, the dominant mechanism for transit peptide evolution was determined. Alterations that resulted in an apparent shift of the start site were prioritized, regardless of insertion or deletion size. If an alternative start site was not present, the mechanism responsible for the highest number of changes was selected as the dominant mechanism. Italicized datasets represent subsets of the Multi-Genome (Merged) dataset, and are presented to demonstrate that the proportion of each mechanism was similar in each subset. 
1 Table 3: Sources of Transit Peptide Evolution by Dataset. For each cluster, the dominant

2 mechanism for transit peptide evolution was determined. Alterations that resulted in an apparent

3 shift of the start site were prioritized, regardless of insertion or deletion size. If an alternative

4 start site was not present, the mechanism responsible for the highest number of changes was

5 selected as the dominant mechanism. Italicized datasets represent subsets of the Multi-Genome

6 (Merged) dataset, and are presented to demonstrate that the proportion of each mechanism was

7 similar in each subset.

\begin{tabular}{|l|c|c|c|c|c|c|}
\hline \multicolumn{1}{|c|}{ Dataset } & NPTPs & Substitution & Alternative & Alternative & Independent & Independent \\
Start Site & Start Site & Insertion & \\
(Insertion) & & & & & & \\
\hline Arabidopsis1001 & 181 & $179(98.9 \%)$ & $0(0.0 \%)$ & $0(0.0 \%)$ & $0(0.0 \%)$ & $2(1.1 \%)$ \\
\hline BrachyPan & 2,272 & $643(28.3 \%)$ & $457(20.1 \%)$ & $259(11.4 \%)$ & $446(19.6 \%)$ & $468(20.6 \%)$ \\
\hline $\begin{array}{l}\text { Multi-Genome- } \\
\text { Merged }\end{array}$ & 2,592 & $832(31.4 \%)$ & $780(29.4 \%)$ & $230(8.7 \%)$ & $539(20.3 \%)$ & $269(10.2 \%)$ \\
\hline $\begin{array}{l}\text { Multi-Genome- } \\
\text { RBH only }\end{array}$ & 430 & $158(36.2 \%)$ & $103(23.6 \%)$ & $27(6.2 \%)$ & $100(22.9 \%)$ & $49(11.2 \%)$ \\
\hline $\begin{array}{l}\text { Multi-Genome- } \\
\text { UCLUST only }\end{array}$ & 1,061 & $361(33.4 \%)$ & $277(25.6 \%)$ & $109(10.1 \%)$ & $209(19.3 \%)$ & $126(11.6 \%)$ \\
\hline $\begin{array}{l}\text { Multi-Genome- } \\
\text { Consensus }\end{array}$ & 1,101 & $313(27.7 \%)$ & $400(35.4 \%)$ & $94(8.3 \%)$ & $230(20.3 \%)$ & $94(8.3 \%)$ \\
\hline
\end{tabular}

8 


\section{Table 4 (on next page)}

GO enrichment of Nascent Plastid-Targeted Proteins in Taxonomically Diverse Species

Significance at FDR $<0.05$ is shown for under- and over-represented terms. Terms associated with chloroplasts and localization were rare in NPTPs, while terms associated with metabolism, biosynthesis, gene expression, and protein interactions were highly enriched. 
2 Table 4: GO enrichment of Nascent Plastid-Targeted Proteins in Taxonomically Diverse

3 Species. Significance at FDR $<0.05$ is shown for under- and over-represented terms. Terms

4 associated with chloroplasts and localization were rare in NPTPs, while terms associated with

5 metabolism, biosynthesis, gene expression, and protein interactions were highly enriched.

6

\begin{tabular}{|c|c|c|c|c|c|}
\hline Tags & GO ID & GO Name & GO Category & FDR & P-Value \\
\hline UNDER & GO:0051179 & localization & BIOLOGICAL_PROCESS & $5.06 \mathrm{E}-03$ & $\begin{array}{l}1.77 \mathrm{E}- \\
05\end{array}$ \\
\hline UNDER & GO:0051234 & establishment of localization & BIOLOGICAL_PROCESS & $5.67 \mathrm{E}-03$ & $\begin{array}{c}2.04 \mathrm{E}- \\
05\end{array}$ \\
\hline UNDER & GO:0006810 & transport & BIOLOGICAL_PROCESS & $6.37 \mathrm{E}-03$ & $\begin{array}{c}2.35 \mathrm{E}- \\
05\end{array}$ \\
\hline UNDER & GO:0009607 & response to biotic stimulus & BIOLOGICAL_PROCESS & $2.28 \mathrm{E}-02$ & $\begin{array}{c}9.61 \mathrm{E}- \\
05\end{array}$ \\
\hline UNDER & GO:0016020 & membrane & CELLULAR_COMPONENT & $2.12 \mathrm{E}-06$ & $\begin{array}{c}2.47 \mathrm{E}- \\
09\end{array}$ \\
\hline UNDER & GO:0009579 & thylakoid & CELLULAR_COMPONENT & $1.29 \mathrm{E}-02$ & $\begin{array}{c}5.22 \mathrm{E}- \\
05\end{array}$ \\
\hline UNDER & GO:0009536 & plastid & CELLULAR_COMPONENT & $3.36 \mathrm{E}-02$ & $\begin{array}{c}1.51 \mathrm{E}- \\
04\end{array}$ \\
\hline OVER & GO:0031323 & $\begin{array}{l}\text { regulation of cellular } \\
\text { metabolic process }\end{array}$ & BIOLOGICAL_PROCESS & $1.46 \mathrm{E}-06$ & $\begin{array}{c}1.35 \mathrm{E}- \\
09\end{array}$ \\
\hline OVER & GO:0032774 & RNA biosynthetic process & BIOLOGICAL_PROCESS & $1.46 \mathrm{E}-06$ & $\begin{array}{c}1.05 \mathrm{E}- \\
09\end{array}$ \\
\hline OVER & GO:0097659 & $\begin{array}{l}\text { nucleic acid-templated } \\
\text { transcription }\end{array}$ & BIOLOGICAL_PROCESS & $1.46 \mathrm{E}-06$ & $\begin{array}{c}9.99 \mathrm{E}- \\
10\end{array}$ \\
\hline OVER & GO:0051171 & $\begin{array}{l}\text { regulation of nitrogen } \\
\text { compound metabolic process }\end{array}$ & BIOLOGICAL_PROCESS & $1.46 \mathrm{E}-06$ & $\begin{array}{c}1.16 \mathrm{E}- \\
09\end{array}$ \\
\hline OVER & GO:0034654 & $\begin{array}{l}\text { nucleobase-containing } \\
\text { compound biosynthetic } \\
\text { process }\end{array}$ & BIOLOGICAL_PROCESS & $1.46 \mathrm{E}-06$ & $\begin{array}{l}8.66 \mathrm{E}- \\
10\end{array}$ \\
\hline OVER & GO:0006351 & $\begin{array}{l}\text { transcription, DNA- } \\
\text { templated }\end{array}$ & BIOLOGICAL_PROCESS & $1.46 \mathrm{E}-06$ & $\begin{array}{l}9.99 \mathrm{E}- \\
10\end{array}$ \\
\hline OVER & GO:0019219 & regulation of nucleobase- & BIOLOGICAL_PROCESS & $1.46 \mathrm{E}-06$ & $1.58 \mathrm{E}-$ \\
\hline
\end{tabular}




\begin{tabular}{|c|c|c|c|c|c|}
\hline & & $\begin{array}{l}\text { containing compound } \\
\text { metabolic process }\end{array}$ & & & 09 \\
\hline OVER & GO:0080090 & $\begin{array}{l}\text { regulation of primary } \\
\text { metabolic process }\end{array}$ & BIOLOGICAL_PROCESS & $1.46 \mathrm{E}-06$ & $\begin{array}{c}1.55 \mathrm{E}- \\
09\end{array}$ \\
\hline OVER & GO:2000112 & $\begin{array}{l}\text { regulation of cellular } \\
\text { macromolecule biosynthetic } \\
\text { process }\end{array}$ & BIOLOGICAL_PROCESS & $2.43 \mathrm{E}-06$ & $\begin{array}{c}3.22 \mathrm{E}- \\
09\end{array}$ \\
\hline OVER & GO:0031326 & $\begin{array}{l}\text { regulation of cellular } \\
\text { biosynthetic process }\end{array}$ & BIOLOGICAL_PROCESS & $2.43 \mathrm{E}-06$ & $\begin{array}{c}4.25 \mathrm{E}- \\
09\end{array}$ \\
\hline OVER & GO:1903506 & $\begin{array}{l}\text { regulation of nucleic acid- } \\
\text { templated transcription }\end{array}$ & BIOLOGICAL_PROCESS & $2.43 \mathrm{E}-06$ & $\begin{array}{c}4.56 \mathrm{E}- \\
09\end{array}$ \\
\hline OVER & GO:2001141 & $\begin{array}{l}\text { regulation of RNA } \\
\text { biosynthetic process }\end{array}$ & BIOLOGICAL_PROCESS & $2.43 \mathrm{E}-06$ & $\begin{array}{c}4.61 \mathrm{E}- \\
09\end{array}$ \\
\hline OVER & GO:0009889 & $\begin{array}{l}\text { regulation of biosynthetic } \\
\text { process }\end{array}$ & BIOLOGICAL_PROCESS & $2.43 \mathrm{E}-06$ & $\begin{array}{c}4.80 \mathrm{E}- \\
09\end{array}$ \\
\hline OVER & GO:0010556 & $\begin{array}{l}\text { regulation of macromolecule } \\
\text { biosynthetic process }\end{array}$ & BIOLOGICAL_PROCESS & $2.43 \mathrm{E}-06$ & $\begin{array}{c}3.29 \mathrm{E}- \\
09\end{array}$ \\
\hline OVER & GO:0018130 & $\begin{array}{l}\text { heterocycle biosynthetic } \\
\text { process }\end{array}$ & BIOLOGICAL_PROCESS & $2.43 \mathrm{E}-06$ & $\begin{array}{c}4.77 \mathrm{E}- \\
09\end{array}$ \\
\hline OVER & GO:0006355 & $\begin{array}{l}\text { regulation of transcription, } \\
\text { DNA-templated }\end{array}$ & BIOLOGICAL_PROCESS & $2.43 \mathrm{E}-06$ & $\begin{array}{c}4.56 \mathrm{E}- \\
09\end{array}$ \\
\hline OVER & GO:1901362 & $\begin{array}{l}\text { organic cyclic compound } \\
\text { biosynthetic process }\end{array}$ & BIOLOGICAL_PROCESS & $3.00 \mathrm{E}-06$ & $\begin{array}{c}6.23 \mathrm{E}- \\
09\end{array}$ \\
\hline OVER & GO:0019438 & $\begin{array}{l}\text { aromatic compound } \\
\text { biosynthetic process }\end{array}$ & BIOLOGICAL_PROCESS & $3.00 \mathrm{E}-06$ & $\begin{array}{c}6.47 \mathrm{E}- \\
09\end{array}$ \\
\hline OVER & GO:0051252 & $\begin{array}{l}\text { regulation of RNA metabolic } \\
\text { process }\end{array}$ & BIOLOGICAL_PROCESS & $3.64 \mathrm{E}-06$ & $\begin{array}{c}8.17 \mathrm{E}- \\
09\end{array}$ \\
\hline OVER & GO:0090304 & $\begin{array}{l}\text { nucleic acid metabolic } \\
\text { process }\end{array}$ & BIOLOGICAL_PROCESS & $3.35 \mathrm{E}-05$ & $\begin{array}{c}7.82 \mathrm{E}- \\
08\end{array}$ \\
\hline OVER & GO:0016070 & RNA metabolic process & BIOLOGICAL_PROCESS & $1.49 \mathrm{E}-04$ & $\begin{array}{c}4.02 \mathrm{E}- \\
07\end{array}$ \\
\hline OVER & GO:0060255 & $\begin{array}{l}\text { regulation of macromolecule } \\
\text { metabolic process }\end{array}$ & BIOLOGICAL_PROCESS & 0.005061 & $\begin{array}{c}1.77 \mathrm{E}- \\
05\end{array}$ \\
\hline OVER & GO:0019222 & $\begin{array}{l}\text { regulation of metabolic } \\
\text { process }\end{array}$ & BIOLOGICAL_PROCESS & 0.009434 & $\begin{array}{c}3.65 \mathrm{E}- \\
05\end{array}$ \\
\hline OVER & GO:0006357 & $\begin{array}{l}\text { regulation of transcription by } \\
\text { RNA polymerase II }\end{array}$ & BIOLOGICAL_PROCESS & 0.010222 & $\begin{array}{c}4.04 \mathrm{E}- \\
05\end{array}$ \\
\hline
\end{tabular}




\begin{tabular}{|c|c|c|c|c|c|}
\hline OVER & GO:0034641 & $\begin{array}{l}\text { cellular nitrogen compound } \\
\text { metabolic process }\end{array}$ & BIOLOGICAL_PROCESS & 0.02888 & $\begin{array}{c}1.27 \mathrm{E}- \\
04\end{array}$ \\
\hline OVER & GO:0010468 & regulation of gene expression & BIOLOGICAL_PROCESS & 0.036366 & $\begin{array}{c}1.67 \mathrm{E}- \\
04\end{array}$ \\
\hline OVER & GO:0090083 & $\begin{array}{l}\text { regulation of inclusion body } \\
\text { assembly }\end{array}$ & BIOLOGICAL_PROCESS & 0.036923 & $\begin{array}{c}1.86 \mathrm{E}- \\
04\end{array}$ \\
\hline OVER & GO:0090084 & $\begin{array}{l}\text { negative regulation of } \\
\text { inclusion body assembly }\end{array}$ & BIOLOGICAL_PROCESS & 0.036923 & $\begin{array}{c}1.86 \mathrm{E}- \\
04\end{array}$ \\
\hline OVER & GO:0070841 & inclusion body assembly & BIOLOGICAL_PROCESS & 0.036923 & $\begin{array}{c}1.86 \mathrm{E}- \\
04\end{array}$ \\
\hline OVER & GO:0005667 & transcription factor complex & CELLULAR_COMPONENT & $2.49 \mathrm{E}-08$ & $\begin{array}{c}2.23 \mathrm{E}- \\
12\end{array}$ \\
\hline OVER & GO:0032777 & $\begin{array}{l}\text { Piccolo NuA4 histone } \\
\text { acetyltransferase complex }\end{array}$ & CELLULAR_COMPONENT & $1.28 \mathrm{E}-06$ & $\begin{array}{c}2.31 \mathrm{E}- \\
10\end{array}$ \\
\hline OVER & GO:0035267 & $\begin{array}{l}\text { NuA4 histone } \\
\text { acetyltransferase complex }\end{array}$ & CELLULAR_COMPONENT & $1.46 \mathrm{E}-06$ & $\begin{array}{c}1.53 \mathrm{E}- \\
09\end{array}$ \\
\hline OVER & GO:0043189 & $\begin{array}{l}\text { H4/H2A histone } \\
\text { acetyltransferase complex }\end{array}$ & CELLULAR_COMPONENT & $1.46 \mathrm{E}-06$ & $\begin{array}{c}1.53 \mathrm{E}- \\
09\end{array}$ \\
\hline OVER & GO:1902562 & $\begin{array}{l}\text { H4 histone acetyltransferase } \\
\text { complex }\end{array}$ & CELLULAR_COMPONENT & $2.43 \mathrm{E}-06$ & $\begin{array}{c}3.73 \mathrm{E}- \\
09\end{array}$ \\
\hline OVER & GO:0000123 & $\begin{array}{l}\text { histone acetyltransferase } \\
\text { complex }\end{array}$ & CELLULAR_COMPONENT & $1.42 \mathrm{E}-04$ & $\begin{array}{c}3.44 \mathrm{E}- \\
07\end{array}$ \\
\hline OVER & GO:1902493 & acetyltransferase complex & CELLULAR_COMPONENT & $1.49 \mathrm{E}-04$ & $\begin{array}{c}3.89 \mathrm{E}- \\
07\end{array}$ \\
\hline OVER & GO:0031248 & $\begin{array}{l}\text { protein acetyltransferase } \\
\text { complex }\end{array}$ & CELLULAR_COMPONENT & $1.49 \mathrm{E}-04$ & $\begin{array}{c}3.89 \mathrm{E}- \\
07\end{array}$ \\
\hline OVER & GO:0044451 & nucleoplasm part & CELLULAR_COMPONENT & $5.93 \mathrm{E}-04$ & $\begin{array}{c}1.65 \mathrm{E}- \\
06\end{array}$ \\
\hline OVER & GO:0090575 & $\begin{array}{l}\text { RNA polymerase II } \\
\text { transcription factor complex }\end{array}$ & CELLULAR_COMPONENT & 0.001407 & $\begin{array}{c}4.05 \mathrm{E}- \\
06\end{array}$ \\
\hline OVER & GO:0044798 & $\begin{array}{l}\text { nuclear transcription factor } \\
\text { complex }\end{array}$ & CELLULAR_COMPONENT & 0.00427 & $\begin{array}{l}1.34 \mathrm{E}- \\
05\end{array}$ \\
\hline OVER & GO:0005669 & $\begin{array}{l}\text { transcription factor TFIID } \\
\text { complex }\end{array}$ & CELLULAR_COMPONENT & 0.004629 & $\begin{array}{c}1.54 \mathrm{E}- \\
05\end{array}$ \\
\hline OVER & GO:1990234 & transferase complex & CELLULAR_COMPONENT & 0.00769 & $\begin{array}{c}2.90 \mathrm{E}- \\
05\end{array}$ \\
\hline OVER & GO:0016864 & intramolecular & MOLECULAR_FUNCTION & 0.001435 & $4.38 \mathrm{E}-$ \\
\hline
\end{tabular}




\begin{tabular}{|c|c|c|c|c|c|}
\hline & & $\begin{array}{l}\text { oxidoreductase activity, } \\
\text { transposing S-S bonds }\end{array}$ & & & 06 \\
\hline OVER & GO:0003756 & $\begin{array}{l}\text { protein disulfide isomerase } \\
\text { activity }\end{array}$ & MOLECULAR_FUNCTION & 0.001435 & $\begin{array}{c}4.38 \mathrm{E}- \\
06\end{array}$ \\
\hline OVER & GO:0005515 & protein binding & MOLECULAR_FUNCTION & 0.004535 & $\begin{array}{c}1.47 \mathrm{E}- \\
05\end{array}$ \\
\hline OVER & GO:0016901 & $\begin{array}{l}\text { oxidoreductase activity, } \\
\text { acting on the } \mathrm{CH}-\mathrm{OH} \text { group } \\
\text { of donors, quinone or similar } \\
\text { compound as acceptor }\end{array}$ & MOLECULAR_FUNCTION & 0.022345 & $\begin{array}{l}9.24 \mathrm{E}- \\
05\end{array}$ \\
\hline OVER & GO:0016671 & $\begin{array}{l}\text { oxidoreductase activity, } \\
\text { acting on a sulfur group of } \\
\text { donors, disulfide as acceptor }\end{array}$ & MOLECULAR_FUNCTION & 0.02337 & $\begin{array}{c}1.01 \mathrm{E}- \\
04\end{array}$ \\
\hline OVER & GO:0047405 & $\begin{array}{l}\text { pyrimidine-5'-nucleotide } \\
\text { nucleosidase activity }\end{array}$ & MOLECULAR_FUNCTION & 0.036923 & $\begin{array}{c}1.86 \mathrm{E}- \\
04\end{array}$ \\
\hline OVER & GO:0044183 & protein folding chaperone & MOLECULAR_FUNCTION & 0.036923 & $\begin{array}{c}1.86 \mathrm{E}- \\
04\end{array}$ \\
\hline
\end{tabular}

7

8 


\section{Table 5 (on next page)}

GO enrichment of Arabidopsis1001 NPTPs

Due to the small number of final NPTPs in this dataset, no results were significant at an FDR $<0.05$ significance threshold. Therefore, data significant at $p$-value $<0.05$ is presented. 
1 Table 5: GO enrichment of Arabidopsis1001 NPTPs. Due to the small number of final NPTPs

2 in this dataset, no results were significant at an FDR $<0.05$ significance threshold. Therefore,

3 data significant at $\mathrm{p}$-value $<0.05$ is presented.

\begin{tabular}{|c|c|c|c|c|c|}
\hline Tags & GO ID & GO Name & GO Category & $\begin{array}{l}\mathrm{FD} \\
\mathrm{R}\end{array}$ & P-Value \\
\hline UNDER & GO:0043227 & membrane-bounded organelle & CELLULAR_COMPONENT & 1 & 0.014882 \\
\hline UNDER & GO:0043231 & $\begin{array}{l}\text { intracellular membrane-bounded } \\
\text { organelle }\end{array}$ & CELLULAR_COMPONENT & 1 & 0.014882 \\
\hline UNDER & GO:0071704 & $\begin{array}{l}\text { organic substance metabolic } \\
\text { process }\end{array}$ & BIOLOGICAL_PROCESS & 1 & 0.033193 \\
\hline UNDER & GO:0044238 & primary metabolic process & BIOLOGICAL_PROCESS & 1 & 0.010442 \\
\hline OVER & GO:0042726 & $\begin{array}{l}\text { flavin-containing compound } \\
\text { metabolic process }\end{array}$ & BIOLOGICAL_PROCESS & 1 & $2.15 \mathrm{E}-02$ \\
\hline OVER & GO:0042727 & $\begin{array}{l}\text { flavin-containing compound } \\
\text { biosynthetic process }\end{array}$ & BIOLOGICAL_PROCESS & 1 & $2.15 \mathrm{E}-02$ \\
\hline OVER & GO:0006662 & glycerol ether metabolic process & BIOLOGICAL_PROCESS & 1 & $3.21 \mathrm{E}-02$ \\
\hline OVER & GO:0009231 & riboflavin biosynthetic process & BIOLOGICAL_PROCESS & 1 & $2.15 \mathrm{E}-02$ \\
\hline OVER & GO:0003919 & $\begin{array}{l}\text { FMN adenylyltransferase } \\
\text { activity }\end{array}$ & MOLECULAR_FUNCTION & 1 & $1.62 \mathrm{E}-02$ \\
\hline OVER & GO:0006766 & vitamin metabolic process & BIOLOGICAL_PROCESS & 1 & $4.78 \mathrm{E}-02$ \\
\hline OVER & GO:0006771 & riboflavin metabolic process & BIOLOGICAL_PROCESS & 1 & $2.15 \mathrm{E}-02$ \\
\hline OVER & GO:0006767 & $\begin{array}{l}\text { water-soluble vitamin metabolic } \\
\text { process }\end{array}$ & BIOLOGICAL_PROCESS & 1 & $4.78 \mathrm{E}-02$ \\
\hline OVER & GO:0004143 & diacylglycerol kinase activity & MOLECULAR_FUNCTION & 1 & $1.62 \mathrm{E}-02$ \\
\hline OVER & GO:0007205 & $\begin{array}{l}\text { protein kinase } \mathrm{C} \text {-activating } \mathrm{G} \\
\text { protein-coupled receptor } \\
\text { signaling pathway }\end{array}$ & BIOLOGICAL_PROCESS & 1 & $1.62 \mathrm{E}-02$ \\
\hline OVER & GO:0007186 & $\begin{array}{l}\text { G protein-coupled receptor } \\
\text { signaling pathway }\end{array}$ & BIOLOGICAL_PROCESS & 1 & $2.68 \mathrm{E}-02$ \\
\hline OVER & GO:0042364 & $\begin{array}{l}\text { water-soluble vitamin } \\
\text { biosynthetic process }\end{array}$ & BIOLOGICAL_PROCESS & 1 & 4.78E-02 \\
\hline OVER & GO:0070566 & adenylyltransferase activity & MOLECULAR_FUNCTION & 1 & $2.68 \mathrm{E}-02$ \\
\hline OVER & GO:0016757 & $\begin{array}{l}\text { transferase activity, transferring } \\
\text { glycosyl groups }\end{array}$ & MOLECULAR_FUNCTION & 1 & $2.80 \mathrm{E}-02$ \\
\hline OVER & GO:0016758 & $\begin{array}{l}\text { transferase activity, transferring } \\
\text { hexosyl groups }\end{array}$ & MOLECULAR_FUNCTION & 1 & $1.99 \mathrm{E}-02$ \\
\hline
\end{tabular}




\begin{tabular}{|l|l|l|l|r|r|} 
OVER & GO:0009110 & vitamin biosynthetic process & BIOLOGICAL_PROCESS & 1 & $4.78 \mathrm{E}-02$ \\
\hline OVER & GO:0018904 & ether metabolic process & BIOLOGICAL_PROCESS & 1 & 0.03212 \\
\hline
\end{tabular}

4

5 


\section{Table 6(on next page)}

GO enrichment of BrachyPan NPTPs

Due to the small number of final NPTPs in this dataset, few results were found using FDR $<$ 0.05 as a significance threshold. Therefore, data significant at $p$-value $<0.05$ is presented. 
1 Table 6: GO enrichment of BrachyPan NPTPs. Due to the small number of final NPTPs in

2 this dataset, few results were found using FDR $<0.05$ as a significance threshold. Therefore, data

3 significant at $\mathrm{p}$-value $<0.05$ is presented.

\begin{tabular}{|c|c|c|c|c|c|}
\hline Tags & GO ID & GO Name & GO Category & FDR & P-Value \\
\hline UNDER & GO:0005737 & cytoplasm & CELLULAR_COMPONENT & 0.026818 & $2.10 \mathrm{E}-04$ \\
\hline UNDER & GO:0044444 & cytoplasmic part & CELLULAR_COMPONENT & 0.045423 & $5.32 \mathrm{E}-04$ \\
\hline UNDER & GO:0005198 & $\begin{array}{l}\text { structural } \\
\text { molecule activity }\end{array}$ & MOLECULAR_FUNCTION & 0.106841 & 0.002523 \\
\hline UNDER & GO:0003735 & $\begin{array}{l}\text { structural } \\
\text { constituent of } \\
\text { ribosome }\end{array}$ & MOLECULAR_FUNCTION & 0.155505 & 0.005467 \\
\hline UNDER & GO:1990904 & $\begin{array}{l}\text { ribonucleoprotein } \\
\text { complex }\end{array}$ & CELLULAR_COMPONENT & 0.178068 & 0.007651 \\
\hline UNDER & GO:0005840 & ribosome & CELLULAR_COMPONENT & 0.178068 & 0.007651 \\
\hline UNDER & GO:1901363 & $\begin{array}{l}\text { heterocyclic } \\
\text { compound } \\
\text { binding }\end{array}$ & MOLECULAR_FUNCTION & 0.37075 & 0.036206 \\
\hline UNDER & GO:0003676 & $\begin{array}{l}\text { nucleic acid } \\
\text { binding }\end{array}$ & MOLECULAR_FUNCTION & 0.37075 & 0.036206 \\
\hline UNDER & GO:0097159 & $\begin{array}{l}\text { organic cyclic } \\
\text { compound } \\
\text { binding }\end{array}$ & MOLECULAR_FUNCTION & 0.37075 & 0.036206 \\
\hline OVER & GO:0043167 & ion binding & MOLECULAR_FUNCTION & $8.38 \mathrm{E}-05$ & $3.27 \mathrm{E}-07$ \\
\hline OVER & GO:0005488 & binding & MOLECULAR_FUNCTION & 0.064876 & $1.01 \mathrm{E}-03$ \\
\hline OVER & GO:0071941 & $\begin{array}{l}\text { nitrogen cycle } \\
\text { metabolic process }\end{array}$ & BIOLOGICAL_PROCESS & 0.106841 & $2.38 \mathrm{E}-03$ \\
\hline OVER & GO:0071554 & $\begin{array}{l}\text { cell wall } \\
\text { organization or } \\
\text { biogenesis }\end{array}$ & BIOLOGICAL_PROCESS & 0.106841 & 0.002921 \\
\hline OVER & GO:0051276 & chromosome & BIOLOGICAL_PROCESS & 0.117522 & 0.003673 \\
\hline
\end{tabular}




\begin{tabular}{|c|c|c|c|c|c|}
\hline & & organization & & & \\
\hline OVER & GO:0043233 & organelle lumen & CELLULAR_COMPONENT & 0.269756 & 0.015806 \\
\hline OVER & GO:0070013 & $\begin{array}{l}\text { intracellular } \\
\text { organelle lumen }\end{array}$ & CELLULAR_COMPONENT & 0.269756 & 0.015806 \\
\hline OVER & GO:0031981 & nuclear lumen & CELLULAR_COMPONENT & 0.269756 & 0.015806 \\
\hline OVER & GO:0031974 & $\begin{array}{l}\text { membrane- } \\
\text { enclosed lumen }\end{array}$ & CELLULAR_COMPONENT & 0.269756 & 0.015806 \\
\hline OVER & GO:0006629 & $\begin{array}{l}\text { lipid metabolic } \\
\text { process }\end{array}$ & BIOLOGICAL_PROCESS & 0.279342 & 0.017459 \\
\hline OVER & GO:0005654 & nucleoplasm & CELLULAR_COMPONENT & 0.348322 & 0.028573 \\
\hline OVER & GO:0016301 & kinase activity & MOLECULAR_FUNCTION & 0.348322 & 0.023589 \\
\hline OVER & GO:0120025 & $\begin{array}{l}\text { plasma membrane } \\
\text { bounded cell } \\
\text { projection }\end{array}$ & CELLULAR_COMPONENT & 0.348322 & 0.028467 \\
\hline OVER & GO:0042995 & cell projection & CELLULAR_COMPONENT & 0.348322 & 0.028467 \\
\hline OVER & GO:0005929 & cilium & CELLULAR_COMPONENT & 0.348322 & 0.028467 \\
\hline OVER & GO:0016772 & $\begin{array}{l}\text { transferase } \\
\text { activity, } \\
\text { transferring } \\
\text { phosphorus- } \\
\text { containing groups }\end{array}$ & MOLECULAR_FUNCTION & 0.37075 & 0.034041 \\
\hline OVER & GO:0065007 & $\begin{array}{l}\text { biological } \\
\text { regulation }\end{array}$ & BIOLOGICAL_PROCESS & 0.375382 & 0.038125 \\
\hline OVER & GO:0003824 & catalytic activity & MOLECULAR_FUNCTION & 0.401607 & 0.042357 \\
\hline OVER & GO:0044428 & nuclear part & CELLULAR_COMPONENT & 0.424632 & 0.046444 \\
\hline
\end{tabular}


Figure 1

Amino Acid Compositional Changes in Transit Peptides

The first 60 residues of Arabidopsis proteins validated by mass spectrometry were analyzed for residue composition and compared with the average residue composition of all Arabidopsis proteins. Extreme enrichment was observed for alanine, proline, arginine, and serine, while significant depletion was found for aspartic acid, glutamine, isoleucine, lysine, asparagine, and tyrosine. Although glycine, leucine, threonine, and valine were abundant, they did not differ significantly from the average residue content in Arabidopsis proteins.

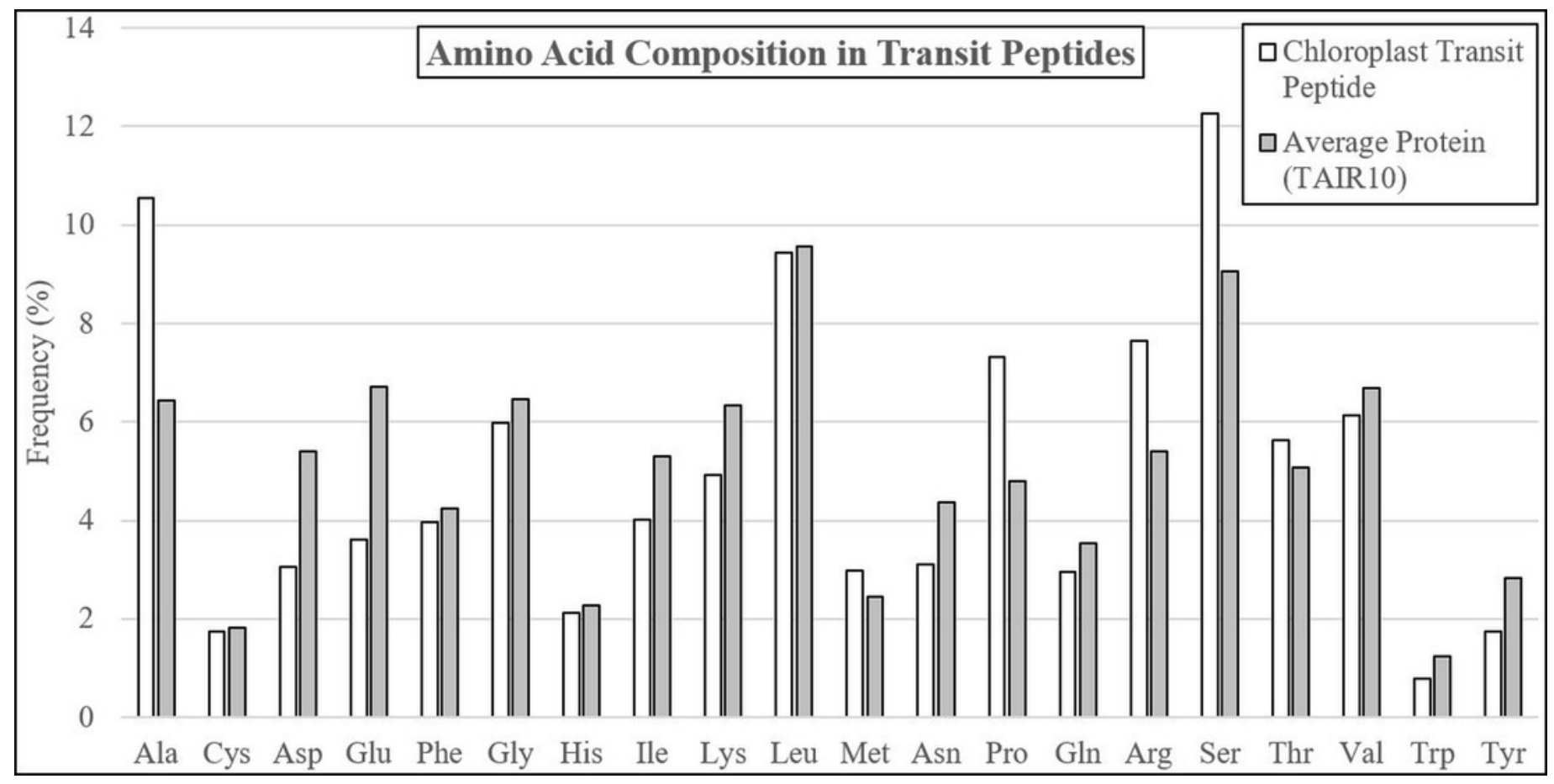




\section{Figure 2}

Residue Frequency in Predicted and Experimentally-Validated Transit Peptides

The first 60 residues of sequences validated to be plastid-targeted by mass spectrometry methods (solid lines) and of predicted plastid-targeted proteins in 15 plant genomes (dotted lines) were collected, and residue composition was assessed for each position. Positions 1 and 2 are omitted from each graph due to skew by methionine and alanine, respectively. Frequency patterns match almost exactly between experimentally-validated and predicted plastid-targeted proteins, but there are differences in the absolute frequency for many amino acids, in particular, highly-enriched and highly-depleted residues. 


\begin{tabular}{|c|c|c|c|}
\hline 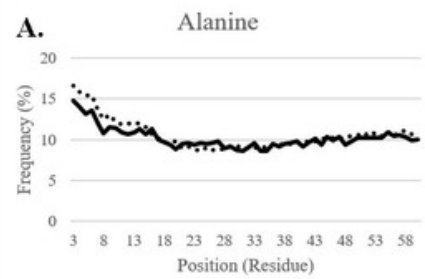 & 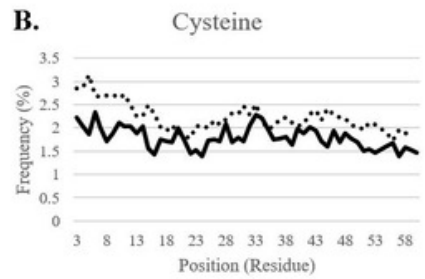 & C. & 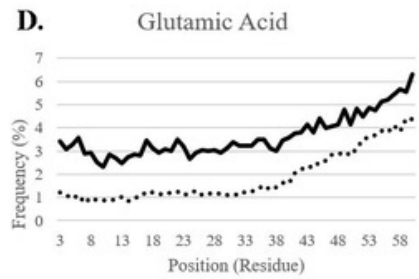 \\
\hline 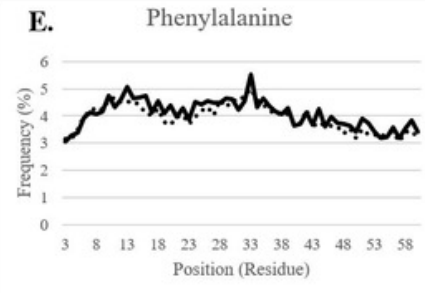 & $\begin{array}{lllllll} & \\
\end{array}$ & 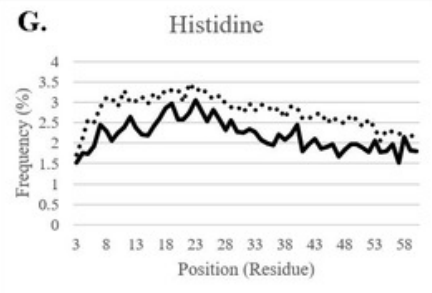 & 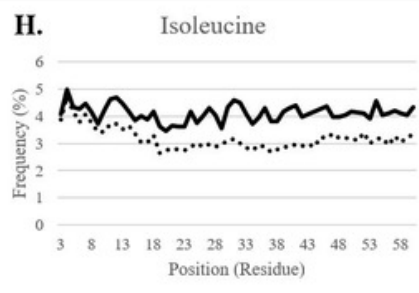 \\
\hline 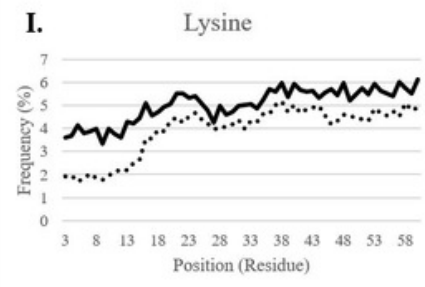 & 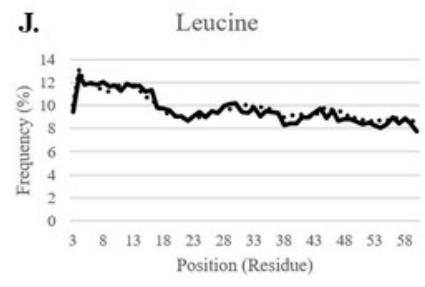 & 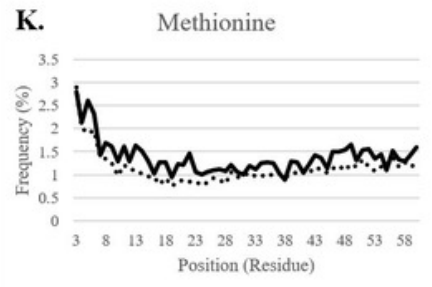 & 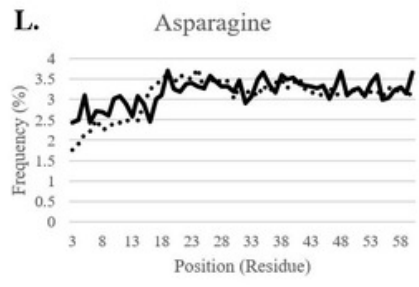 \\
\hline 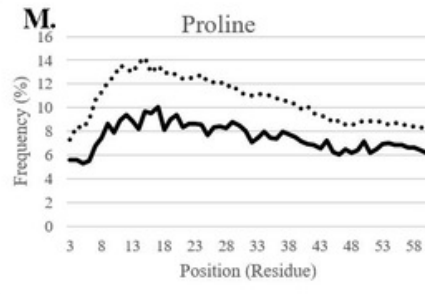 & 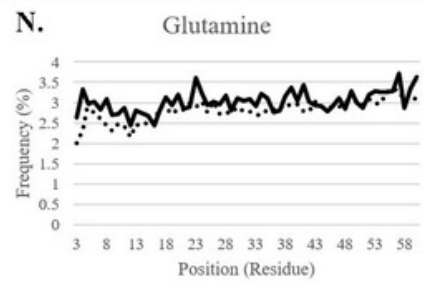 & $\begin{array}{l}\text { O. Arginine } \\
14\end{array}$ & 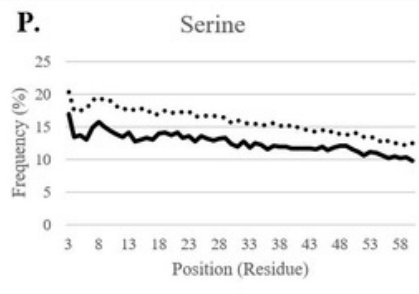 \\
\hline 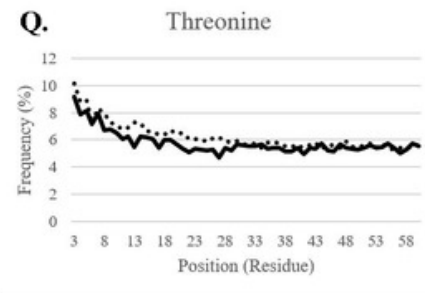 & 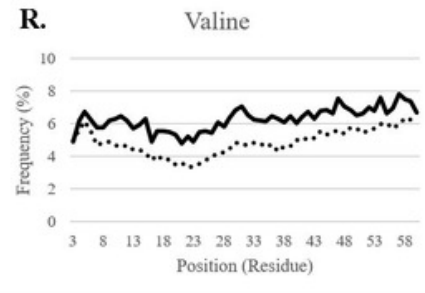 & S. & 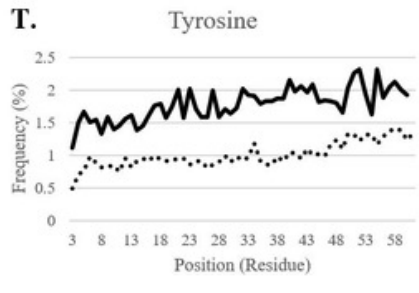 \\
\hline
\end{tabular}




\section{Figure 3}

Residue Composition of Predicted Transit Peptides and Whole Proteome Sequence

(A) Residue composition of predicted transit peptides shows significant enrichment in alanine, leucine, proline, arginine, and serine in all assessed organisms, but monocot homologs were highly overrepresented in alanine, proline, and arginine. Corresponding decreases in serine and many of the minor amino acids including phenylalanine, isoleucine, lysine, and asparagine were also found in monocot sequences. $A$. trichopoda sequences closely matched eudicot sequences. (B) Alanine was about $2 \%$ higher within the whole proteomes of monocot species, but this does not explain the extreme differences found for predicted transit peptides. 


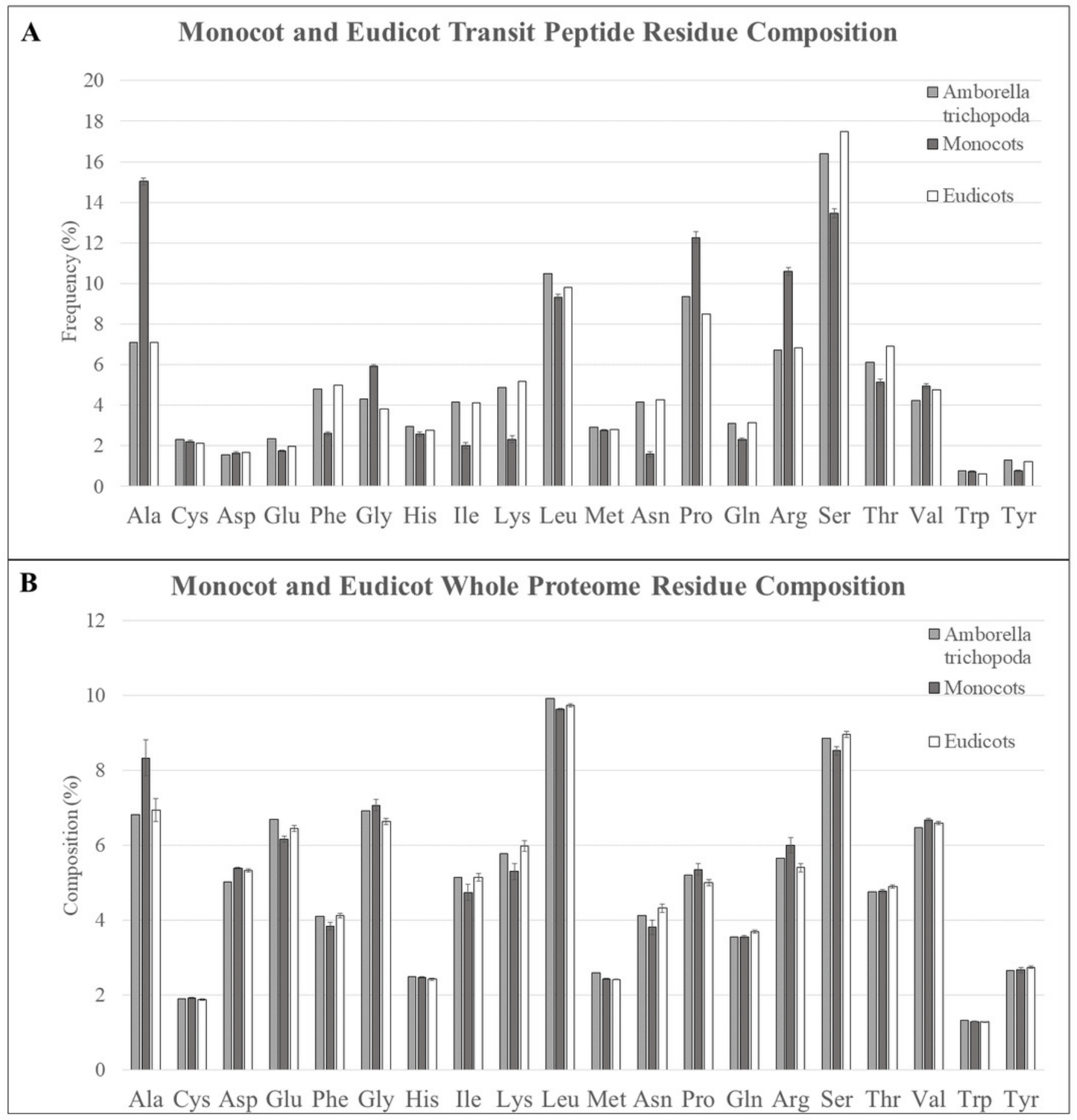




\section{Figure 4}

Illustration of Phylogenetics Workflow

For each candidate cluster representing a potential NPTP, the steps for filtering, alignment, tree prediction, and mutation analysis are depicted. Blue boxes indicate the path of candidate clusters, red boxes indicate sequences or clusters that are filtered out, green boxes indicate the potential mutational categories, and programs or conditions used in the workflow are indicated to the right of arrows. 


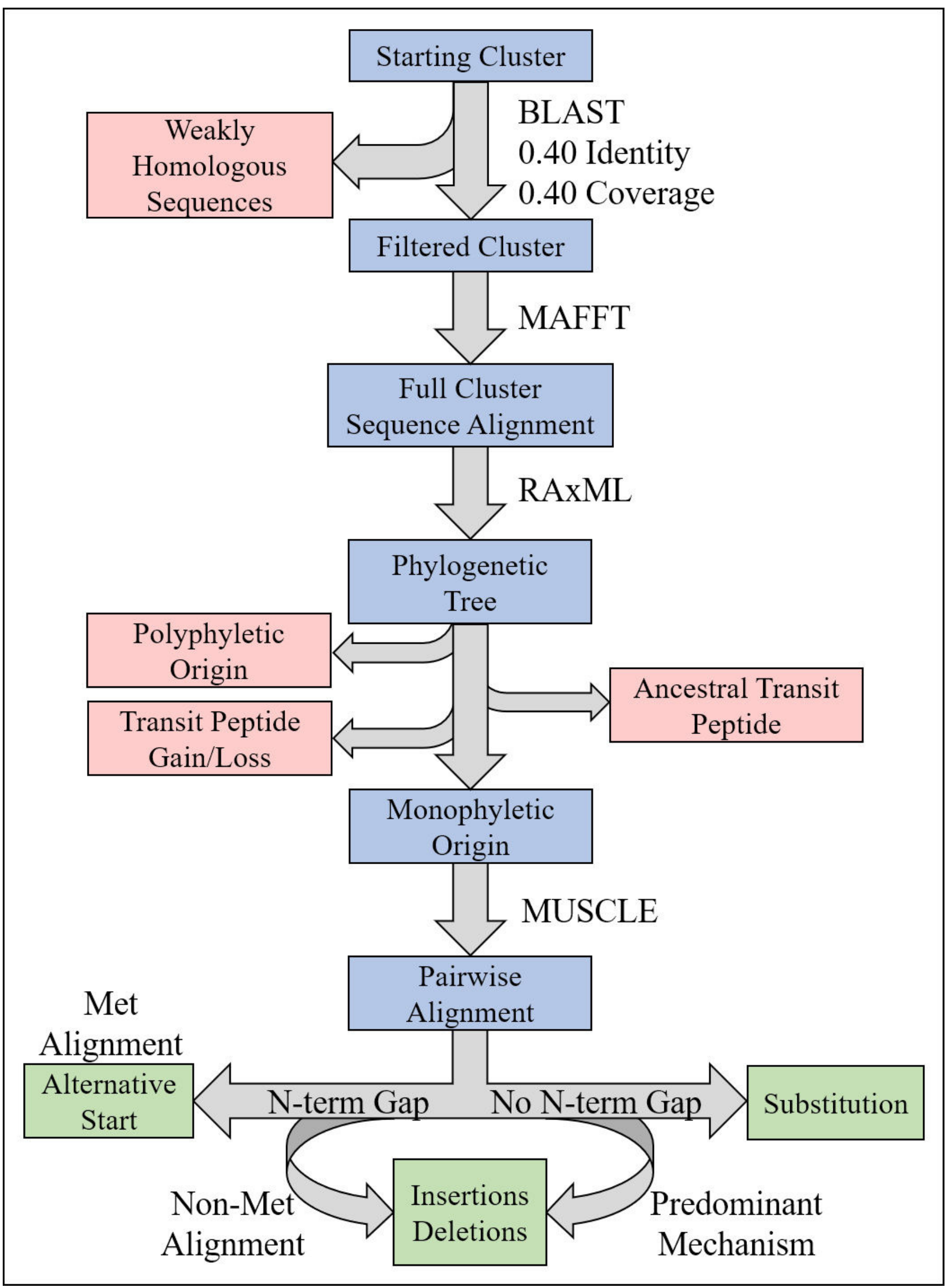




\section{Figure 5}

Models of Transit Peptide Evolution

In each panel, exons are indicated with shaded boxes and introns with black lines. The ancestral RNA molecule is indicated in black, and variants are indicated in light green.

Substitution variants are the only mechanism requiring a change to the DNA sequence, although sequence variants may also promote or hinder the other mechanisms. Adapted from Davis et al., 2006 .

\begin{tabular}{|c|c|c|}
\hline Mechanism & Illustration & Description \\
\hline A. Substitution & 5' $\begin{array}{c}\text { Mutation } \\
\nabla \\
\\
\end{array}$ & $\begin{array}{l}\text { Ancestral Gene } \\
\text { Plastid-Targeted } \\
\text { Non-Plastidial }\end{array}$ \\
\hline $\begin{array}{l}\text { B. Alternative } \\
\text { Initiation } \\
\text { Exon }\end{array}$ & $\begin{array}{r}1 \mathrm{a} \\
\square 1 \mathrm{~b}\end{array}$ & $\begin{array}{l}\text { Ancestral Gene } \\
\text { Plastid-Targeted } \\
\text { Non-Plastidial }\end{array}$ \\
\hline $\begin{array}{c}\text { C. Alternative } \\
\text { Splice } \\
\text { Variant }\end{array}$ & $\begin{array}{r}1 \\
\quad 1\end{array}$ & $\begin{array}{l}\text { Ancestral Gene } \\
\text { Plastid-Targeted } \\
\text { Non-Plastidial }\end{array}$ \\
\hline $\begin{array}{l}\text { D. Alternative } \\
\text { Start } \\
\text { Site }\end{array}$ & Start(1) Start (2) & $\begin{array}{l}\text { Ancestral Gene } \\
\text { Plastid-Targeted } \\
\text { Non-Plastidial }\end{array}$ \\
\hline
\end{tabular}




\section{Figure 6}

\section{Mutation Sources in Multi-Genome NPTPs}

Merged results for RBH, UCLUST, and Consensus datasets are presented here. (A) Clusters in which an upstream alternative start site caused the acquisition of a transit peptide were most abundant, followed by substitutions and insertions. Deletions were comparatively rare. (B) A slight but significant linear decrease in the amino acid substitution frequency at each position was observed, indicating that positions at the proximal end of the $\mathrm{N}$-terminus have a greater effect on transit peptide prediction strength. (C) Arginine, proline, and serine experienced significant net increases, while aspartic acid, glutamic acid, and glycine all experienced more than $2 \%$ net decrease when nascent transit peptides were compared to the closes non-targeted neighbor sequence. Net change of amino acids was generally similar between substitutions and insertions/deletions, but proline and arginine were far less likely to be acquired due to substitutions. (D) Most insertions and deletions were between 1-5 amino acids in length and generally decreased in frequency as the size increased. However, elements that covered the entirely 60 -residue length of the transit peptide region were extremely abundant, especially those caused by insertions. 


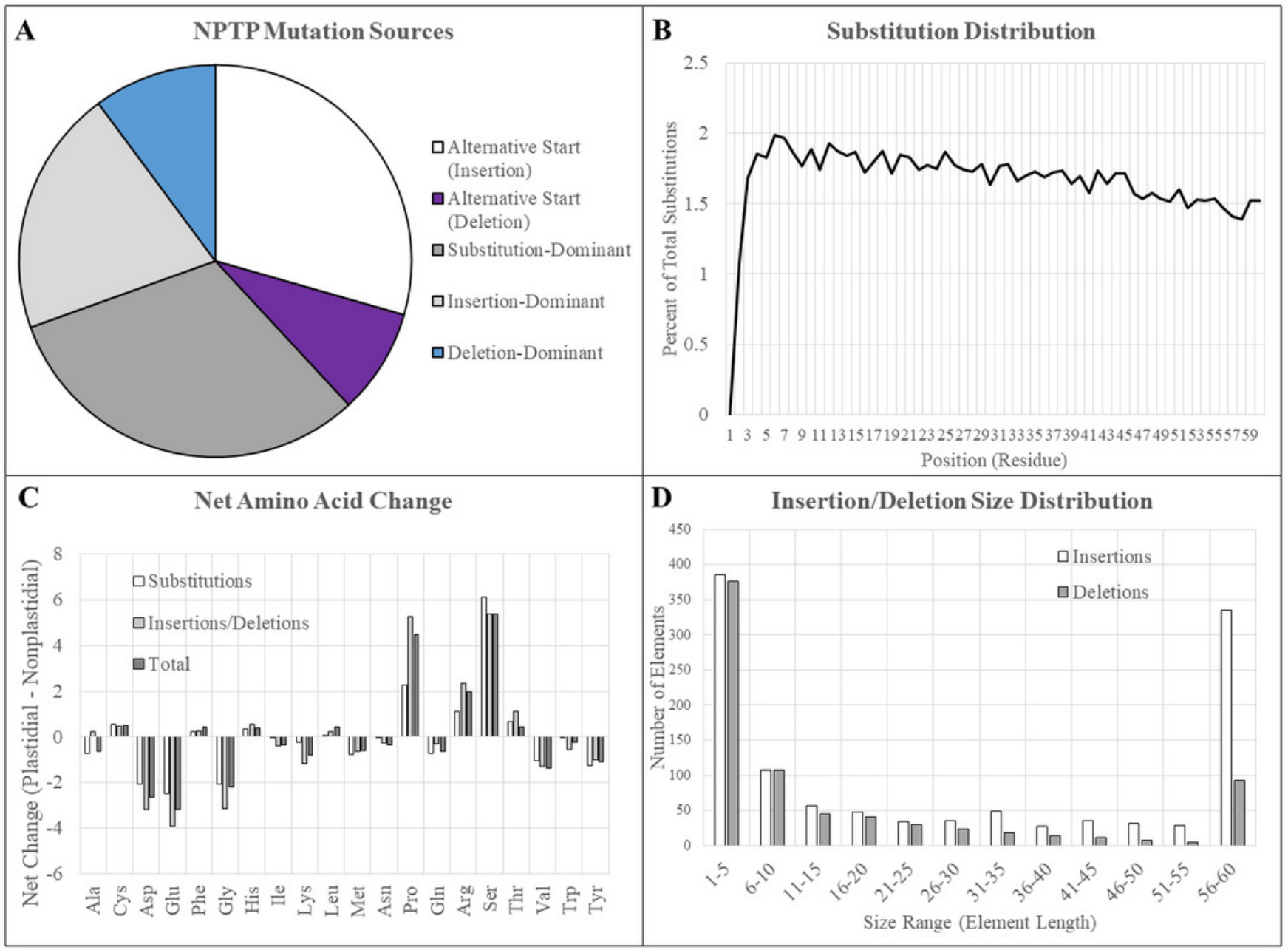




\section{Figure 7}

NPTP Mutation Sources and Characteristics in Arabidopsis1001

(A) The proportion NPTP mechanisms in Arabidopsis1001 showed only one instance of an internal deletion and one instance of a C-terminal deletion causing a difference in targeting prediction, while the remaining instances were caused by substitutions. (B) A significant negative trend in substitution frequency was observed for Arabidopsis1001 sequences, with up to $4 \%$ of substitutions occurring at positions in the proximal end, and $0-1 \%$ of substitutions occurring at positions in the distal end. (C) significant increases in cysteine, asparagine, and serine were observed in the substitutions, while aspartic acid, glutamic acid, and leucine had significant decreases. 


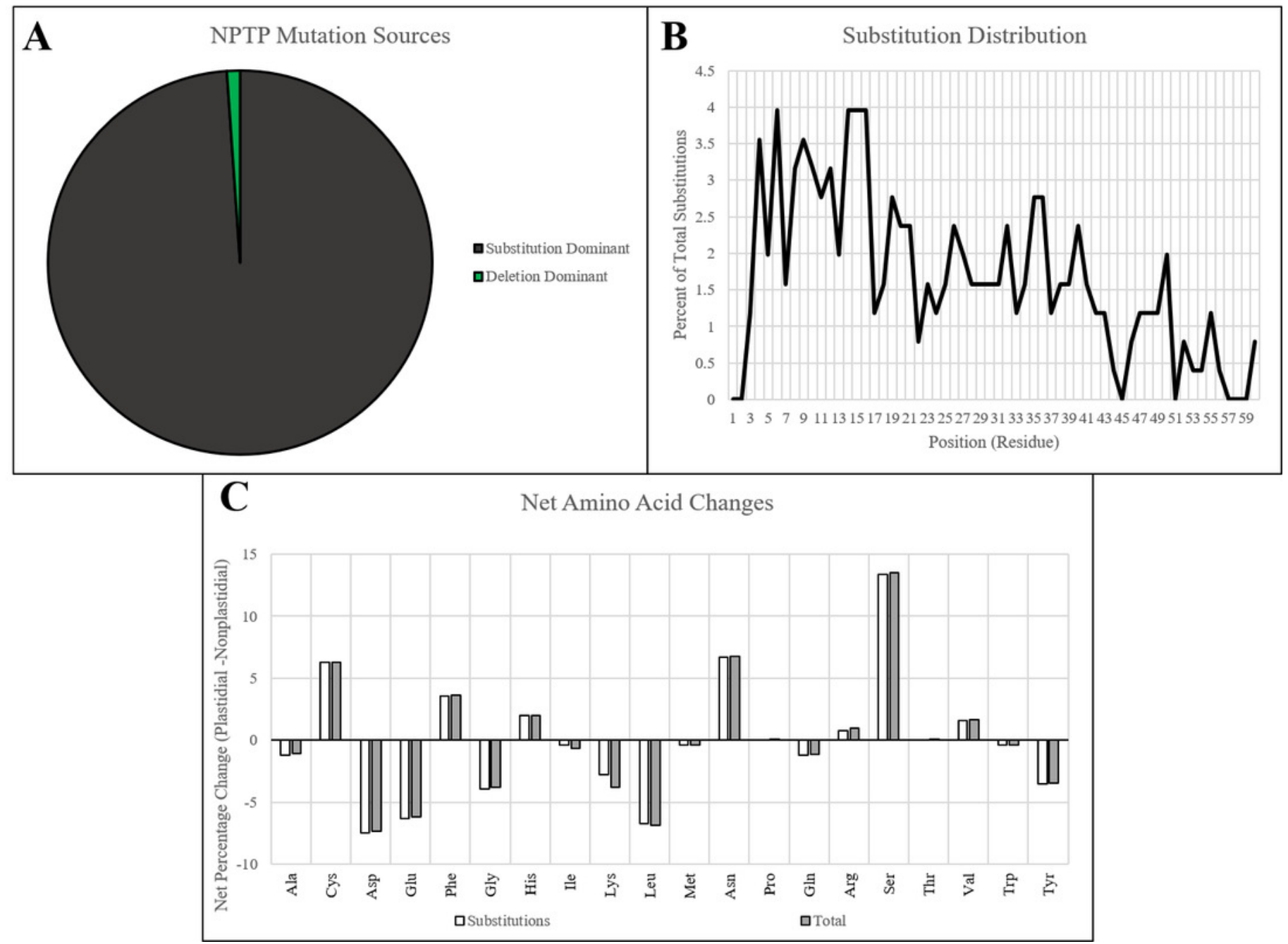




\section{Figure 8}

Geographic Distribution of NPTPs in Arabidopsis1001 Accessions

Taxonomic groups were referenced according to the Arabidopsis1001 Proteomes project, and the number of NPTP's for each accession were added to the respective taxonomic group. The admixed group, of which Columbia-0 is a part of, accounted for the most NPTP's (A) but was overall one of the least diverse taxonomic groups. Relict, Italian/Balkan/Caucasus, and Spanish accessions contained the most NPTPs per genotype, while Asian, Swedish, Germanic, and Central European accessions contained the fewest (B). Geographic distribution is indicated in (C), where shaded circular areas are indicative of magnitude. Taxonomic groups are color-coded according to Joshi et al., 2012 .

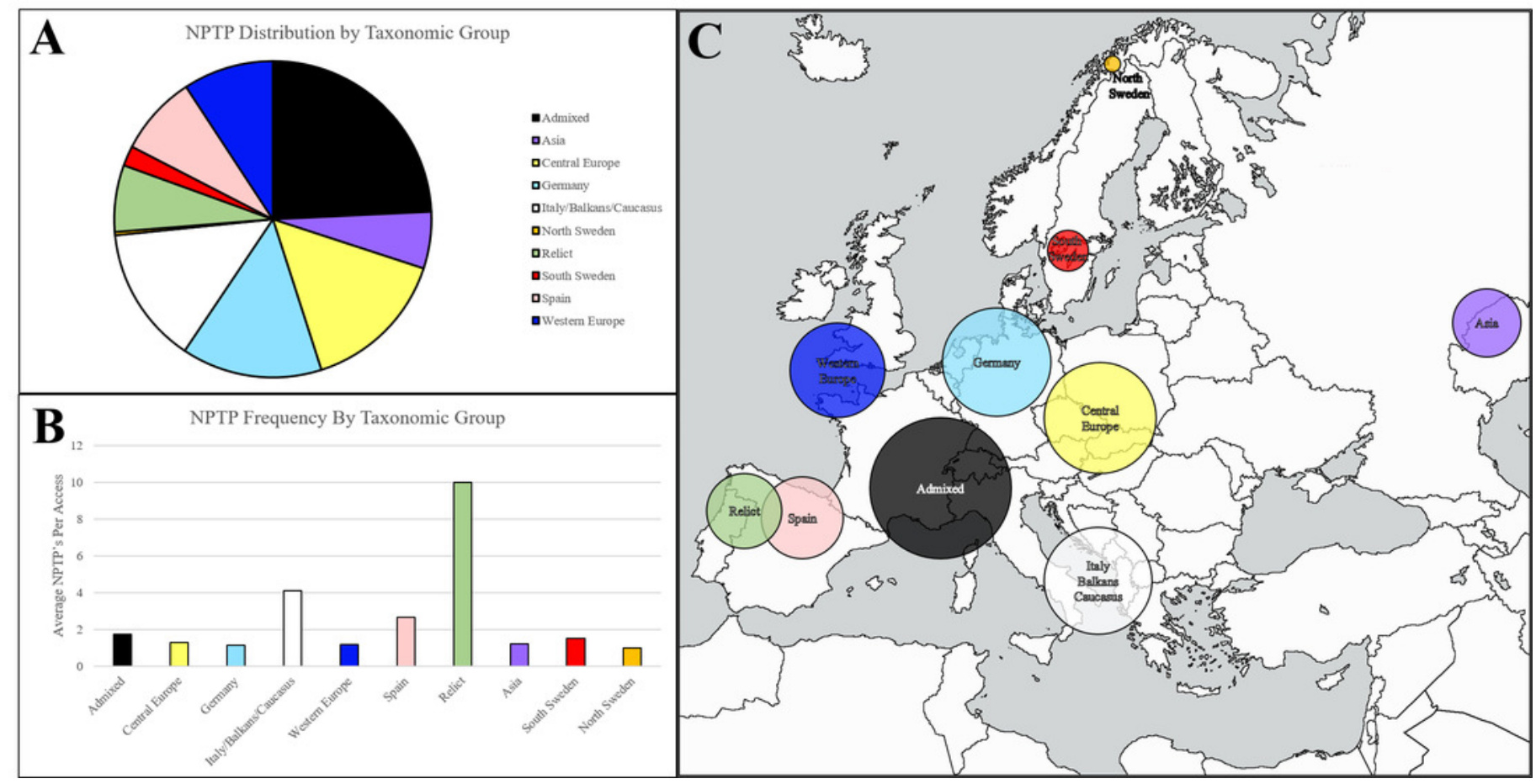




\section{Figure 9}

Type and Characteristics of Mutations in BrachyPan NPTPs

(A) Substitutions were most dominant at $28.3 \%$, followed by independent deletions, upstream alternative start sites, and independent deletions. (B) Substitution frequency was greatest at the proximal end and decreased linearly to the distal end. (C) the net change in residue composition favored increases in proline, arginine, serine, and threonine in transit peptides, while aspartic and glutamic acids, glycine, and leucine had $2 \%$ or greater decreases. (D) Insertions or deletions which covered the entirety of the transit peptide region were most abundant, indicating possible exon swapping. Of the remaining elements, smaller elements were most abundant and decreased in frequency with increasing size. 


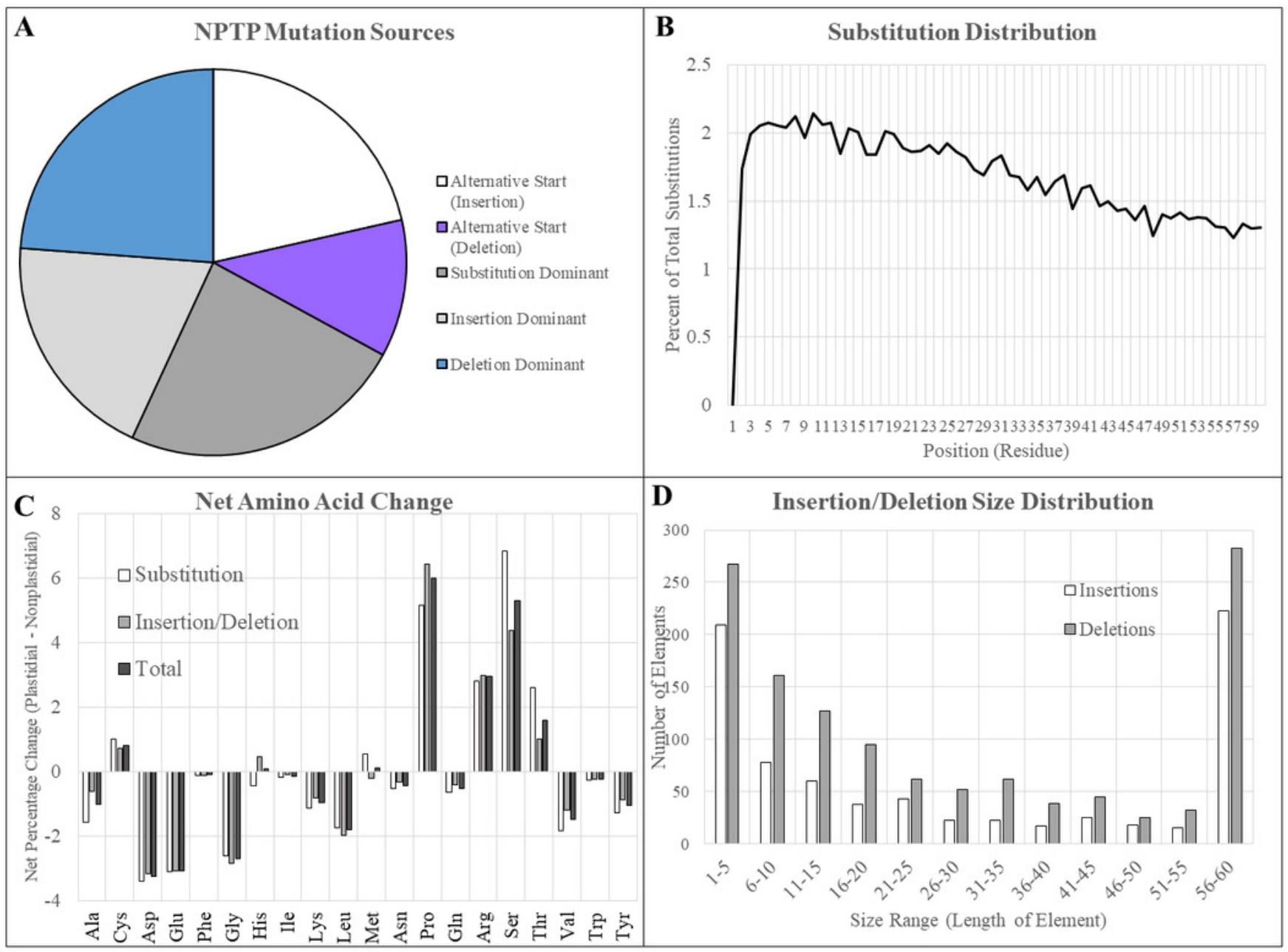


Figure 10

Geographic Distribution of NPTPs in BrachyPan Accessions

The Turkish $(T+)$ taxonomic group had the most NPTPs in absolute numbers $(A)$, but when measured per accession, the extremely-delayed flowering taxonomic group (EDF+) was nearly twice as divergent (B). Geographic distribution of these lines is indicated in (C), where the length of each bar corresponds the number of NPTPs for each labeled accession. Taxonomic groups are color-coded according to Gordon et al., 2017 .

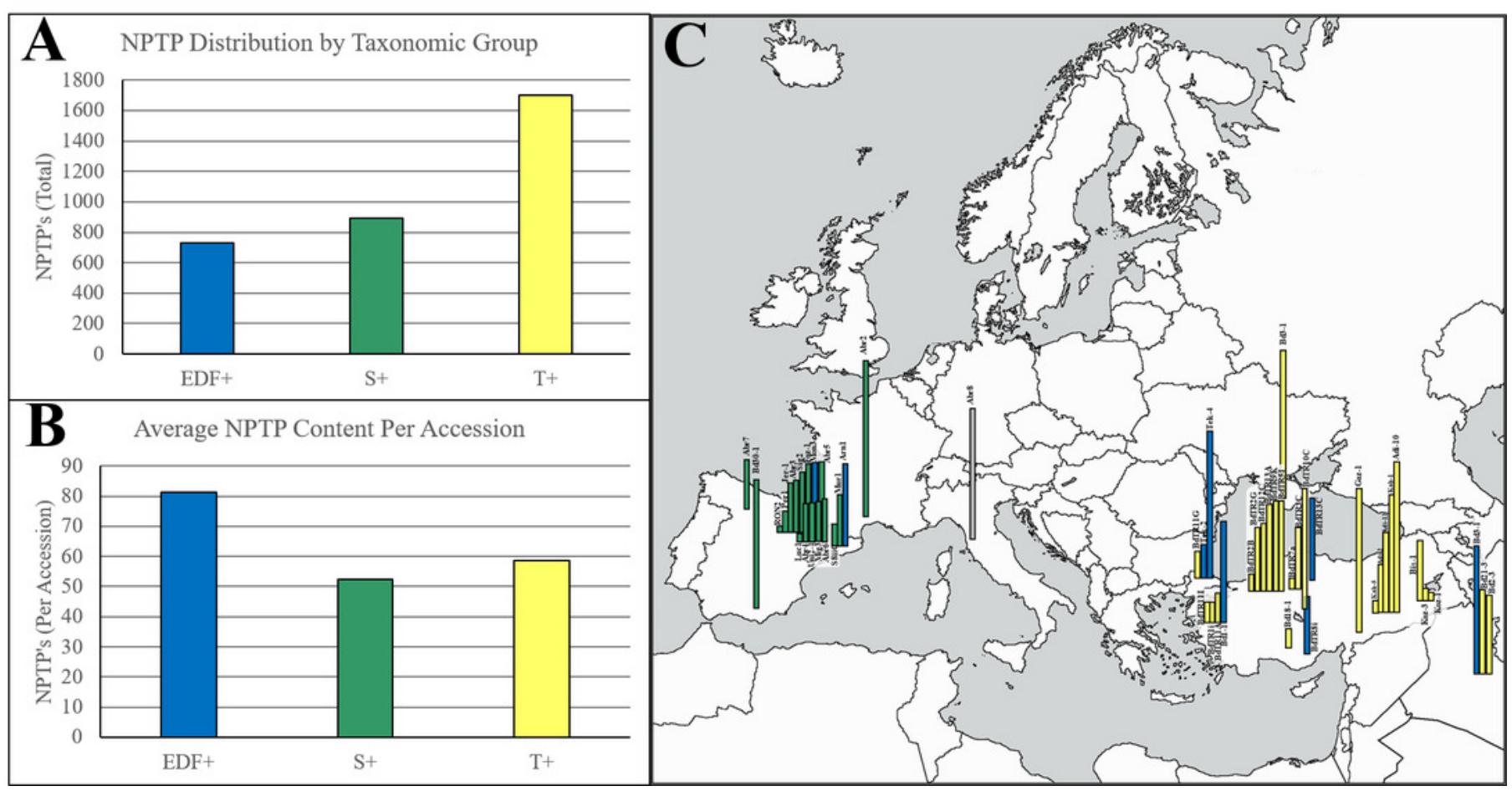




\section{Figure 11}

\section{Gene Conservation of NPTPs in BrachyPan}

"Core" genes are those shared by all 56 accessions, "Softcore" genes are shared by 53-55 accessions, "Shell" genes are shared by 3-52 accessions, "Cloud" genes are found in 1-2 accessions. While most gene clusters reported by Gordon et al. are in the "Shell" category, the "Core" and "Softcore" categories accounted for the most NPTPs. Categories are colorcoded according to Gordon et al. (2017).

A BrachyPan Gene Conservation of PlastidTargeted Clusters

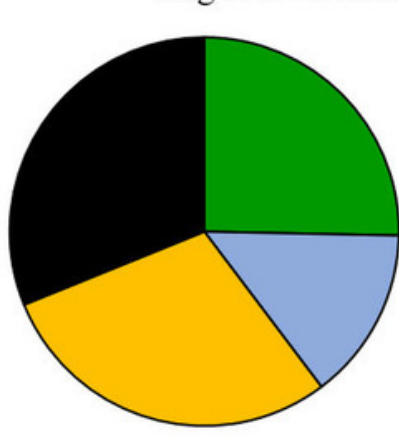

B BrachyPan Gene Conservation of NPTPs

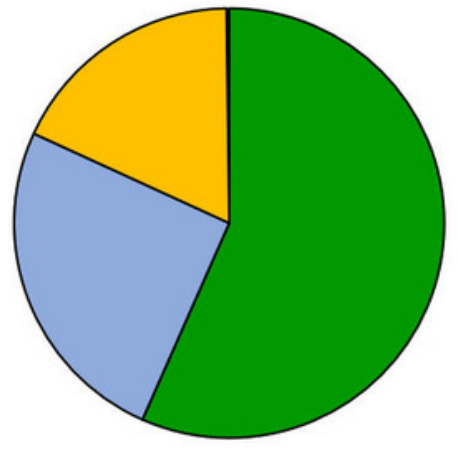

